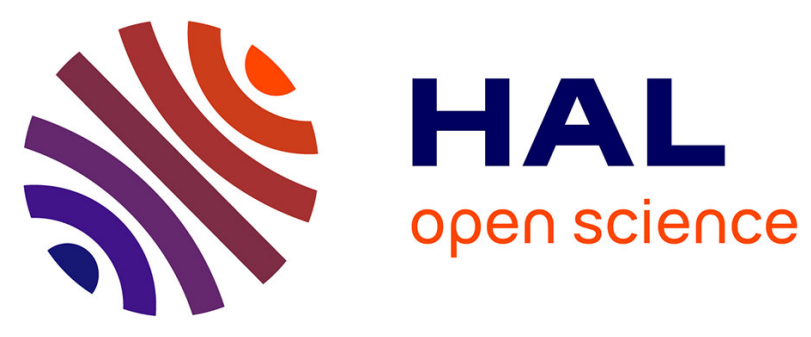

\title{
Magma redox and structural controls on iron isotope variations in Earth's mantle and crust
}

Nicolas E Dauphas, Mathieu Roskosz, Esen Ercan Alp, Daniel R. Neuville, Michael Yu Hu, Corliss Kin I Sio, François Tissot, Jiyong Zhao, Laurent Tissandier, Etienne Médard, et al.

\section{To cite this version:}

Nicolas E Dauphas, Mathieu Roskosz, Esen Ercan Alp, Daniel R. Neuville, Michael Yu Hu, et al.. Magma redox and structural controls on iron isotope variations in Earth's mantle and crust. Earth and Planetary Science Letters, 2014, 398, pp.127-140. 10.1016/j.epsl.2014.04.033 . hal-01130702

\section{HAL Id: hal-01130702 https://hal.science/hal-01130702}

Submitted on 19 Nov 2021

HAL is a multi-disciplinary open access archive for the deposit and dissemination of scientific research documents, whether they are published or not. The documents may come from teaching and research institutions in France or abroad, or from public or private research centers.
L'archive ouverte pluridisciplinaire HAL, est destinée au dépôt et à la diffusion de documents scientifiques de niveau recherche, publiés ou non, émanant des établissements d'enseignement et de recherche français ou étrangers, des laboratoires publics ou privés.

\section{(c) (1) $\$$}

Distributed under a Creative Commons Attribution - NonCommercial| 4.0 International 


\title{
Magma redox and structural controls on iron isotope variations in Earth's mantle and crust
}

\author{
N. Dauphas ${ }^{\mathrm{a}, *}$, M. Roskosz ${ }^{\mathrm{b}}$, E.E. Alp ${ }^{\mathrm{c}}$, D.R. Neuville ${ }^{\mathrm{d}}$, M.Y. Hu ${ }^{\mathrm{c}}$, C.K. Sio ${ }^{\text {a }}$, F.L.H. Tissot ${ }^{\mathrm{a}}$, \\ J. Zhao ${ }^{c}$, L. Tissandier $^{\mathrm{e}}$, E. Médard $^{\mathrm{f}}$, C. Cordier $^{\mathrm{b}}$

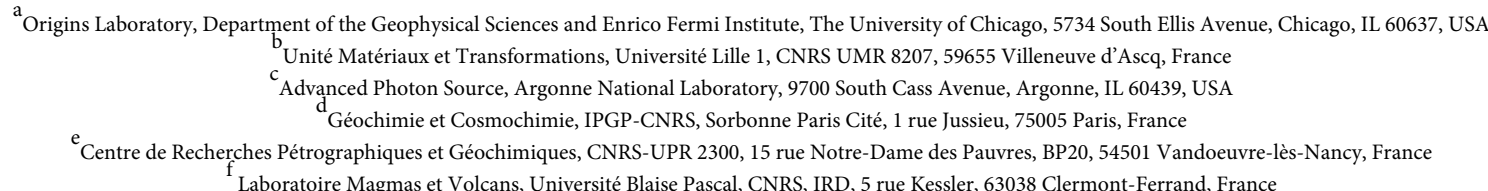

\begin{abstract}
The heavy iron isotopic composition of Earth's crust relative to chondrites has been explained by vaporization during the Moon-forming impact, equilibrium partitioning between metal and silicate at core-mantle-boundary conditions, or partial melting and magma differentiation. The latter view is supported by the observed difference in the iron isotopic compositions of MORBS and peridotites. However, the precise controls on iron isotope variations in igneous rocks remain unknown. Here, we show that equilibrium iron isotope fractionation is mainly controlled by redox ( $\mathrm{Fe}^{3+} / \mathrm{Fe}_{\text {tot }}$ ratio) and structural (e.g., polymerization) conditions in magmas. We measured, for the first time, the mean force constants of iron bonds in silicate glasses by synchrotron Nuclear Resonant Inelastic X-ray Scattering (NRIXS, also known as Nuclear Resonance Vibrational Spectroscopy - NRVS, or Nuclear Inelastic Scattering - NIS). The same samples were studied by conventional Mössbauer and X-ray Absorption Near Edge Structure (XANES) spectroscopy. The NRIXS results reveal a +0.2 to $+0.4 \%$ equilibrium fractionation on ${ }^{56} \mathrm{Fe} /{ }^{54} \mathrm{Fe}$ ratio between $\mathrm{Fe}^{2+}$ and $\mathrm{Fe}^{3+}$ end-members in basalt, andesite, and dacite glasses at magmatic temperatures. These first measurements can already explain $\sim 1 / 3$ of the iron isotopic shift measured in MORBs relative to their source. Further work will be required to investigate how pressure, temperature, and structural differences between melts and glasses affect equilibrium fractionation factors. In addition, large fractionation is also found between rhyolitic glass and commonly occurring oxide and silicate minerals. This fractionation reflects mainly changes in the coordination environment of $\mathrm{Fe}^{2+}$ in rhyolites relative to less silicic magmas and mantle minerals, as also seen by XANES. We provide a new calibration of XANES features vs. $\mathrm{Fe}^{3+} / \mathrm{Fe}_{\text {tot }}$ ratio determinations by Mössbauer to estimate $\mathrm{Fe}^{3+} / \mathrm{Fe}_{\text {tot }}$ ratio in situ in glasses of basaltic, andesitic, dacitic, and rhyolitic compositions. Modeling of magma differentiation using rhyolite-MELTS shows that iron structural changes in silicic magmas can explain the heavy iron isotopic compositions of granitoids and rhyolites. This study demonstrates that iron stable isotopes can help reveal planetary redox conditions and igneous processes. Other heterovalent elements such as Ti, $\mathrm{V}$, $\mathrm{Eu}, \mathrm{Cr}, \mathrm{Ce}$, or $\mathrm{U}$ may show similar isotopic variations in bulk rocks and individual minerals, which could be used to establish past and present redox condition in the mantles of Earth and other planets.
\end{abstract}

\section{Introduction}

Studies of the stable isotopic composition of Earth's mantle for major rock-forming elements other than oxygen are rapidly expanding to new elements but much uncertainty remains as to what those measurements have to tell about the evolution

\footnotetext{
* Corresponding author.

E-mail address: dauphas@uchicago.edu (N. Dauphas).
}

of our planet (Mg: Handler et al., 2009; Teng et al., 2010; Si: Georg et al., 2007; Fitoussi et al., 2009; Savage et al., 2010; Zambardi et al., 2013; Fe: Dauphas and Rouxel, 2006; Weyer and Ionov, 2007; Dauphas et al., 2009a; Craddock et al., 2013; Ca: DePaolo, 2004; Simon and DePaolo, 2010; Huang et al., 2011; K: Humayun and Clayton, 1995). Among these elements, iron is particularly interesting because it possess three oxidation states (metallic $\mathrm{Fe}^{0}$, ferrous $\mathrm{Fe}^{2+}$, and ferric $\mathrm{Fe}^{3+}$ ) that were 
partially separated during core formation and crust extraction. Another advantage of $\mathrm{Fe}$ is that isotopic measurements $\left\{\delta^{56} \mathrm{Fe}=\right.$ $\left[\left({ }^{56} \mathrm{Fe} /{ }^{54} \mathrm{Fe}\right)_{\text {sample }} /\left({ }^{56} \mathrm{Fe} /{ }^{54} \mathrm{Fe}\right)_{\text {IRMM } 014}-1\right] \times 10^{3}$, where IRMM014 is a standard with near-chondritic iron isotopic composition are highly precise and accurate, routinely reaching $\pm 0.03 \%$ by either standard bracketing or isotope dilution (Dauphas et al., 2009b; Craddock and Dauphas, 2011; Millet et al., 2012). A major feature of the Fe isotopic composition of the Earth that remains to be explained is why does the crust (Beard et al., 2003; Poitrasson et al., 2004; Poitrasson and Freydier, 2005; Schoenberg and von Blanckenburg, 2006; Weyer and Ionov, 2007; Heimann et al., 2008; Dauphas et al., 2009a; Telus et al., 2012; Teng et al., 2013) have isotopically heavy $\mathrm{Fe}$ isotopic composition relative to chondrites, the putative building blocks of the Earth (Poitrasson et al., 2005; Schoenberg and von Blanckenburg, 2006; Dauphas et al., 2009a; Craddock and Dauphas, 2011)? Mid-ocean ridge basalts (MORBs) that form the bulk of Earth's oceanic crust have remarkably homogeneous $\mathrm{Fe}$ isotopic composition averaging $\delta^{56} \mathrm{Fe}=+0.105 \pm$ $0.006 \%$ o $(2 \sigma / \sqrt{n}, n=43$, MSWD $=1.9)$ irrespective of degree of differentiation or partial melting (Teng et al., 2013). This is significantly heavier than the Fe isotopic composition of chondrites, which show little variations in $\delta^{56} \mathrm{Fe}$ from one group to another $\left(\delta^{56} \mathrm{Fe}=0.00 \pm 0.014 \%, 2 \sigma / \sqrt{n}, n=41\right.$, MSWD $=9$; Craddock and Dauphas, 2011).

Some have suggested that this shift was a global feature of the silicate Earth, possibly reflecting vaporization during the Moonforming impact (Poitrasson et al., 2004) or metal-silicate partitioning at high pressure (Polyakov, 2009; Williams et al., 2012). Although not definitely ruled out, these scenarios have difficulties (Poitrasson et al., 2009; Liu et al., 2010; Hin et al., 2012; Dauphas et al., 2012; Craddock et al., 2013). In particular, they are predicated on the idea that the Fe isotopic composition of MORBs is representative of that of their source rock. However, studies of xenoliths and peridotite massifs suggest that Earth's mantle has near-chondritic Fe isotopic composition and consequently that the heavy Fe isotopic composition of MORBs reflects isotopic fractionation during partial melting (Weyer et al., 2005; Schoenberg and von Blanckenburg, 2006; Weyer and Ionov, 2007). These results were contended on the basis that the measured peridotites showed significant scatter in their $\delta^{56} \mathrm{Fe}$ values due to metasomatism in the lithospheric mantle, so these samples cannot be taken as representative of the bulk silicate Earth (Beard and Johnson, 2007; Poitrasson et al., 2013; however see Weyer et al., 2007).

Craddock et al. (2013) recently measured the Fe isotopic composition of abyssal peridotites, which directly sample the mantle that produced MORBs. After screening out the most weathered samples by using variations in $\mathrm{Al}_{2} \mathrm{O}_{3} / \mathrm{SiO}_{2}$ vs. $\mathrm{MgO} / \mathrm{SiO}_{2}$, Craddock et al. (2013) concluded that the Fe isotopic composition of the silicate Earth is $+0.025 \pm 0.025 \%$, which is indistinguishable from the chondritic composition and is significantly lower than the MORB composition, implying that Fe isotopes are fractionated during partial melting. These measurements confirm results on high degree partial mantle melts, boninites and komatites, which show nearor sub-chondritic Fe isotopic compositions (Dauphas et al., 2009a, 2010; Hibbert et al., 2012). It is uncertain at present whether the isotopic fractionation between magmas and source rocks is influenced by the oxidized nature of Earth's mantle, where $\mathrm{Fe}^{2+}$ and $\mathrm{Fe}^{3+}$ coexist (Weyer and Ionov, 2007; Dauphas et al., 2009a, 2009b; Williams et al., 2004).

To address this question, we have used the synchrotron technique of NRIXS (Seto et al., 1995; Sturhahn et al., 1995) to derive reduced partition function ratios (or $\beta$-factors) for Fe (Dauphas et al., 2012) in geologically relevant silicate glasses and olivine.

\section{Materials and methods}

\subsection{Material synthesis and chemical characterization}

NRIXS can only detect signal from ${ }^{57} \mathrm{Fe}$, which has a low natural abundance of $2.119 \%$. Therefore, all the materials analyzed in this study were enriched in this isotope to reduce acquisition time. As a proxy for magmas, we prepared glasses of basaltic, andesitic, dacitic, and rhyolitic compositions (Table 1 ). We have also synthesized olivine (Fo82), which is the most abundant mantle mineral.

Glasses were synthesized at the University of Lille (France) from mixtures of reagent grade $\mathrm{SiO}_{2}, \mathrm{Al}_{2} \mathrm{O}_{3}, \mathrm{CaCO}_{3}, \mathrm{MgO}, \mathrm{Na}_{2} \mathrm{CO}_{3}$, $\mathrm{K}_{2} \mathrm{CO}_{3}, \mathrm{TiO}_{2}$, and $\mathrm{Fe}_{2} \mathrm{O}_{3}$ that had been first fired at 300 to $1000^{\circ} \mathrm{C}$. The starting material was melted in air at $1550^{\circ} \mathrm{C}$ for $1 \mathrm{~h}$ in a thin-walled Pt crucible and was then finely crushed. Glasses were then re-melted for $2 \mathrm{~h}$ and quenched on a $\mathrm{Cu}$ plate. For each composition, two batches of starting glass were prepared, one with pure ${ }^{57} \mathrm{Fe}_{2} \mathrm{O}_{3}$ and the other with normal isotopic abundance $\mathrm{Fe}_{2} \mathrm{O}_{3}$. The second batch was used to pre-saturate Pt loops. Final syntheses were performed in vertical gas-mixing furnaces (Gero, CRPG, Nancy, France) using the wire-loop method. The oxygen fugacity $\left(f \mathrm{O}_{2}\right)$ was controlled using $\mathrm{CO} / \mathrm{CO}_{2}$ gas mixtures (Table S1 of Appendix B). Glass droplets of approximately $25 \mathrm{mg}$ were prepared $(\emptyset \simeq 2 \mathrm{~mm}$ ). Wire loops of either Pt or Re had a weight of approximately $13 \mathrm{mg}$. Glass powders were first attached to wire loops using polyvinyl alcohol as a binder and were then melted at $1550^{\circ} \mathrm{C}$. Samples were quenched in air after $2-3 \mathrm{~h}$ in the furnace. This duration was long enough to equilibrate iron oxidation state with the imposed $\mathrm{fO}_{2}$ (Roskosz et al., 2008), while minimizing the loss of volatile elements. Gas flows were recorded and controlled by Millipore mass-flow controllers. Three nominal oxygen fugacities were applied to the samples: $\log \left(f \mathrm{O}_{2}\right) \simeq-0.7$ (air), $\log \left(f \mathrm{O}_{2}\right) \simeq-2.4$ $(\mathrm{QFM}+2.5), \log \left(f \mathrm{O}_{2}\right) \simeq-8$ (IW +0.3$)$. At IW, the solubility of Fe in Pt is very high (Gudmundsson and Holloway, 1993), resulting in saturated wires that are brittle and difficult to handle. To avoid these issues, Re wires were used for synthesis at IW. Because at $\mathrm{QFM}+2.5$, Re is unstable and iron readily alloys with Pt, Pt wires were pre-saturated with Fe for synthesis at QFM +2.5 (e.g., Grove, 1981). These wires were placed in a Pt crucible and immersed in finely crushed glass powder of the parent composition (prepared from regular $\mathrm{Fe}_{2} \mathrm{O}_{3}$ ) and placed in a vertical furnace for $24 \mathrm{~h}$ at $1550^{\circ} \mathrm{C}$ at the $\mathrm{fO}_{2}$ conditions of the final synthesis. The $24 \mathrm{~h} \mathrm{du}-$ ration is sufficient for the Pt wires to be saturated in Fe (Roskosz et al., 2006). Concentrated HF was used to remove the silicate glasses and to clean the saturated Pt wires before use.

Hydrothermal synthesis was used to prepare isotopically enriched olivine. Reagent grade $\mathrm{SiO}_{2}$ and ${ }^{57} \mathrm{Fe}_{2} \mathrm{O}_{3}$ were first mixed in stoichiometric proportions $\left(27.34 \% \mathrm{SiO}_{2}\right.$ and $\left.72.66 \%{ }^{57} \mathrm{Fe}_{2} \mathrm{O}_{3}\right)$ to form pure fayalite. After prolonged grinding in an agate mortar, the powder was poured in a Re crucible (to limit Fe loss) and placed in a vertical gas-mixing furnace (Clermont-Ferrand, France) at $1150{ }^{\circ} \mathrm{C}$ and $\log \left(f \mathrm{O}_{2}\right) \simeq-12\left(\mathrm{H}_{2} / \mathrm{CO}_{2}\right.$ gas mixture $)$ for $48 \mathrm{~h}$. The run product was then ground and annealed a second time under the same experimental conditions. The synthetic fayalite was then mixed with $\mathrm{MgO}$ and $\mathrm{SiO}_{2}$ powders to reach the desired olivine composition $\left(\mathrm{Fo}_{82}\right)$. The second step of the synthesis was performed in a non-endloaded piston cylinder. About $80 \mathrm{mg}$ of the olivine mix was packed in a gold capsule $(4 \mathrm{~mm}$ OD) with $4 \mu \mathrm{L}$ of distilled water. The bottom-cooled capsule was welded and placed in a salt/pyrex/MgO assembly as described in Médard et al. (2006). The synthesis was done at $1000^{\circ} \mathrm{C}$ and $1 \mathrm{GPa}$ for $114 \mathrm{~h}$. The recovered samples consisted of small translucent grains (typically $50-100 \mu \mathrm{m}$ in diameter). Electron microprobe and Raman spectroscopy analyses were performed on several handpicked grains. All the analyzed grains were clean olivine and their com- 


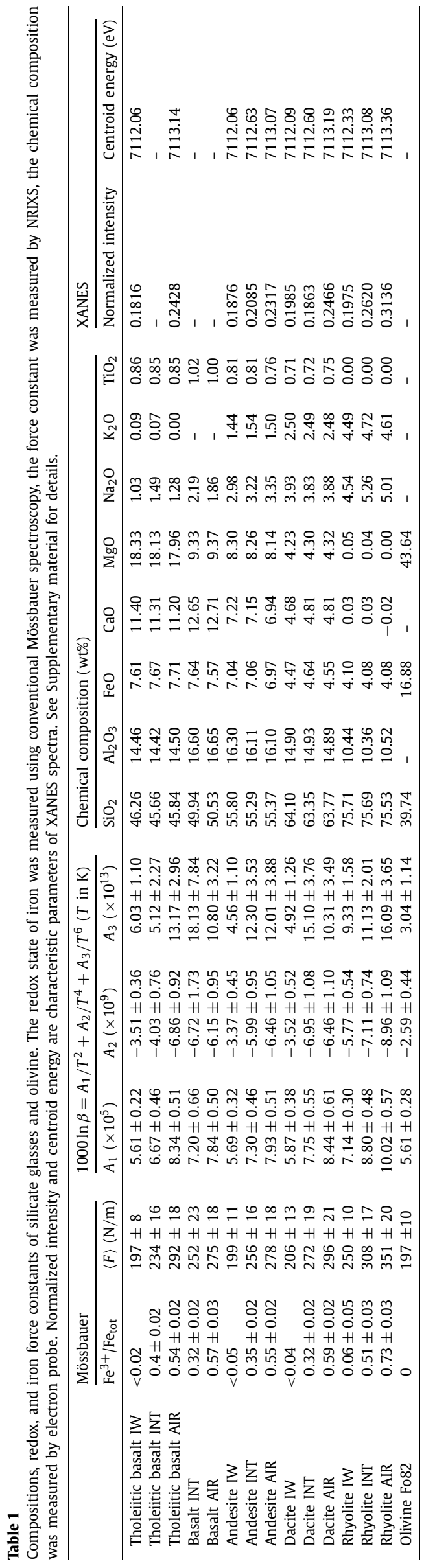

positions are reported in Table S2 of Appendix $\mathrm{B}(\mathrm{Fo \#} \simeq 82$ ). Some opaque inclusions were observed in some grains by optical microscopy and electron microprobe. The absence of a Raman signature indicates that these opaque grains are either pure iron metal or FeO grains. Olivine crystals containing such grains were excluded.

The chemical compositions of glasses and individual olivine grains were determined with an electron microprobe (Cameca SX 100 at the UMET laboratory; University of Lille 1) operating at $15 \mathrm{kV}$ and $15 \mathrm{nA}$ beam current. Albite, $\mathrm{MgO}, \mathrm{Fe}_{2} \mathrm{O}_{3}$, Orthose, wollastonite, $\mathrm{MnTiO}_{3}$ standards were typically used to calibrate the microprobe. Fast mineralogical characterization of olivines was also performed by Raman spectroscopy on a HR labRam spectrometer (Horiba scientific, at LASIR, University Lille 1).

\subsection{Redox determination}

Redox ratios (Table 1 ) were determined by ${ }^{57} \mathrm{Fe}$ resonant $\mathrm{ab}-$ sorption Mössbauer. Mössbauer spectra were collected at the Advanced Photon Source (tholeitic basalts and andesite IW) and UMET (basalts, other andesites, dacites and rhyolites). Analytical details varied from laboratory to laboratory but all the spectra were collected at room temperature. The Mössbauer spectra (Fig. 1) were decomposed using the 2D site-distribution method of Alberto et al. (1996) developed for silicate glasses. The same method had been used by Cottrell et al. (2009) to interpret their results. With this method, spectra are described in terms of Gaussian distributions of isomer shifts and quadrupole splitting, similar to approaches used elsewhere (Lagarec and Rancourt, 1997; Rossano et al., 1999; Wilke et al., 2002; Jayasuriya et al., 2004). The $\mathrm{Fe}^{3+} /\left(\mathrm{Fe}^{3+}+\mathrm{Fe}^{2+}\right)=\mathrm{Fe}^{3+} / \mathrm{Fe}_{\text {tot }}$ ratio was derived from the relative areas of the resonant absorption doublets of $\mathrm{Fe}^{2+}$ and $\mathrm{Fe}^{3+}$. Differences in recoil-free fractions of $\mathrm{Fe}^{2+}$ and $\mathrm{Fe}^{3+}$ in spectra of silicate glasses are small enough that the ratio of absorptions of the $\mathrm{Fe}^{2+}$ and $\mathrm{Fe}^{3+}$ doublets from $298 \mathrm{~K}$ spectra yields an accurate measure of the $\mathrm{Fe}^{3+} / \mathrm{Fe}_{\text {tot }}$ ratio of the glasses (Jayasuriya et al., 2004).

\subsection{XANES spectroscopy}

The X-ray Absorption Near Edge Structure (XANES) measurements (Fig. 2; Table 1 compiles normalized intensities and centroid energies) were made at the BM30B (FAME) beamline of ESRF (Grenoble, France). The storage ring was operated at $6.0 \mathrm{GeV}$ with injection currents of $200 \mathrm{~mA}$ in a $2 / 3$ filling mode. The energy was monochromatized with a conventional double crystal Si (220) monochromator. The photon energy was scanned stepwise by changing the Bragg angle of both Si crystals. Data were collected in fluorescence mode. A more detailed description of the setup can be found in Magnien et al. (2008). All XANES spectra were acquired in the energy range $7100-7300 \mathrm{eV}$ with a reproducibility of $\pm 0.05 \mathrm{eV}$. A reference foil of metallic Fe was used for internal energy calibration of the monochromator. The first inflection point of the Fe K-edge was set at $7111.08 \mathrm{eV}$. The XAS analyses were carried out with the XAFS software package (Winterer, 1997). The baseline was interpolated using a spline function over intervals of several eV to extract the XANES features (Galoisy et al., 2001; Wilke et al., 2001; Magnien et al., 2004, 2008).

\subsection{NRIXS spectroscopy}

Details on the NRIXS technique and its use in isotope geochemistry are explained briefly hereafter (for details, see Chumakov and Sturhahn, 1999; Sturhahn et al., 1995; Seto et al., 1995, and Dauphas et al., 2012). The Mössbauer-sensitive isotope ${ }^{57} \mathrm{Fe}$ has a low-lying nuclear excited state at $14.4125 \mathrm{keV}$. The approach 

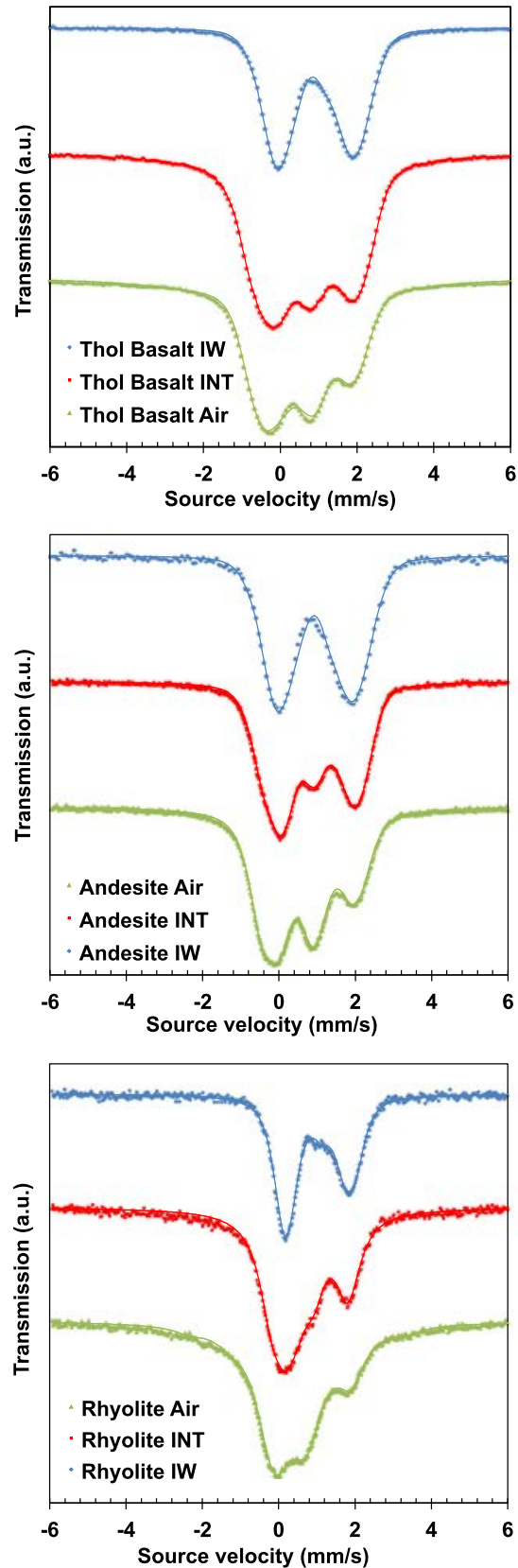
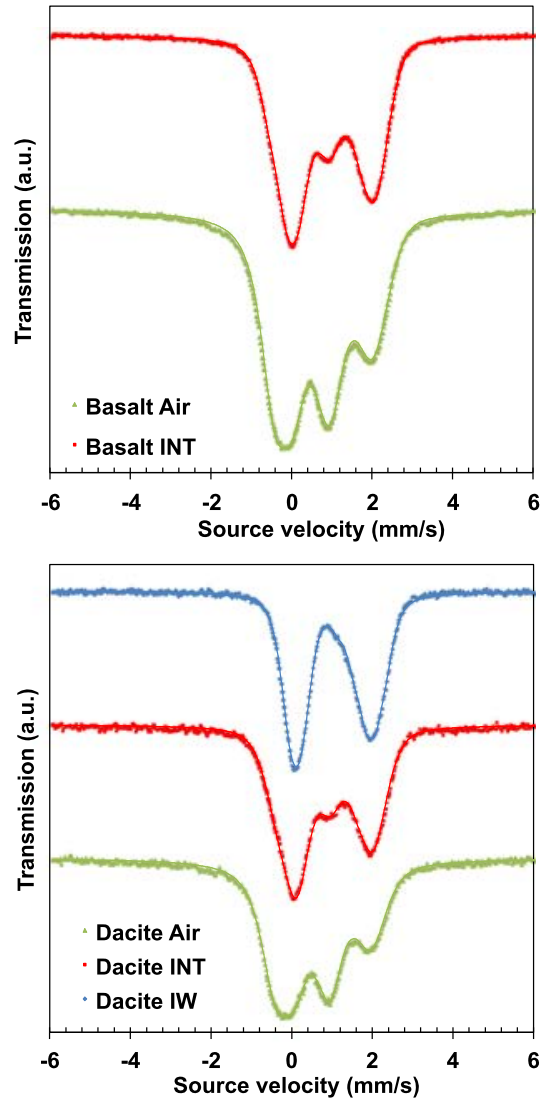

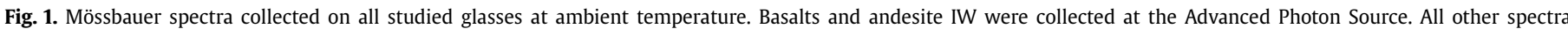
were collected at the University of Lille 1 . The best fits to the data are shown as continuous lines.

used in NRIXS is to scan the energy around this transition energy, typically from -120 to $+130 \mathrm{meV}$ around the nominal resonance energy, and measure X-rays scattered by excitation of the resonant nuclide. The detectors are placed around the sample to maximize the solid angle in which scattered X-rays are collected. Significant nuclear transitions take place at the nominal resonance energy but some transitions also occur when incident X-rays have too low or too high energies. When the incident $\mathrm{X}$-rays have too low energies, some nuclear transitions can take place as normal modes of lattice vibration (or their particle-like equivalents, phonons) can provide the extra kick of energy for the transition to occur. When the incident X-rays have too high energies, some nuclear transitions can still take place if the extra amount of energy can be transferred to exciting normal modes of vibration. Thus, by measuring the X-rays that are scattered by the nuclear transitions as a function of energy of the incident beam, one directly probes the vibration properties of the iron sub-lattice. The signal measured is the scattering function $S(E)$. After elastic peak removal and some normalization, the scattering function can be used to calculate the partial, projected phonon density of states (PDOS). The density of states is the energy distribution of lattice vibrations. Through statistical mechanics, this distribution relates to the thermodynamics of the mineral.

The technique of NRIXS was first applied to isotope geochemistry by Polyakov et al. (2005, 2007), who calculated reduced partition function ratios or $\beta$-factors for Sn and Fe using previously published partial PDOS. The partial PDOS (Fig. 3) is itself derived from the measured scattering probability function $S(E)$ using a Fourier-Log inversion. More recently, Dauphas et al. (2012) and Hu et al. (2013) showed that the $\beta$-factors could be calculated directly from $S(E)$, 

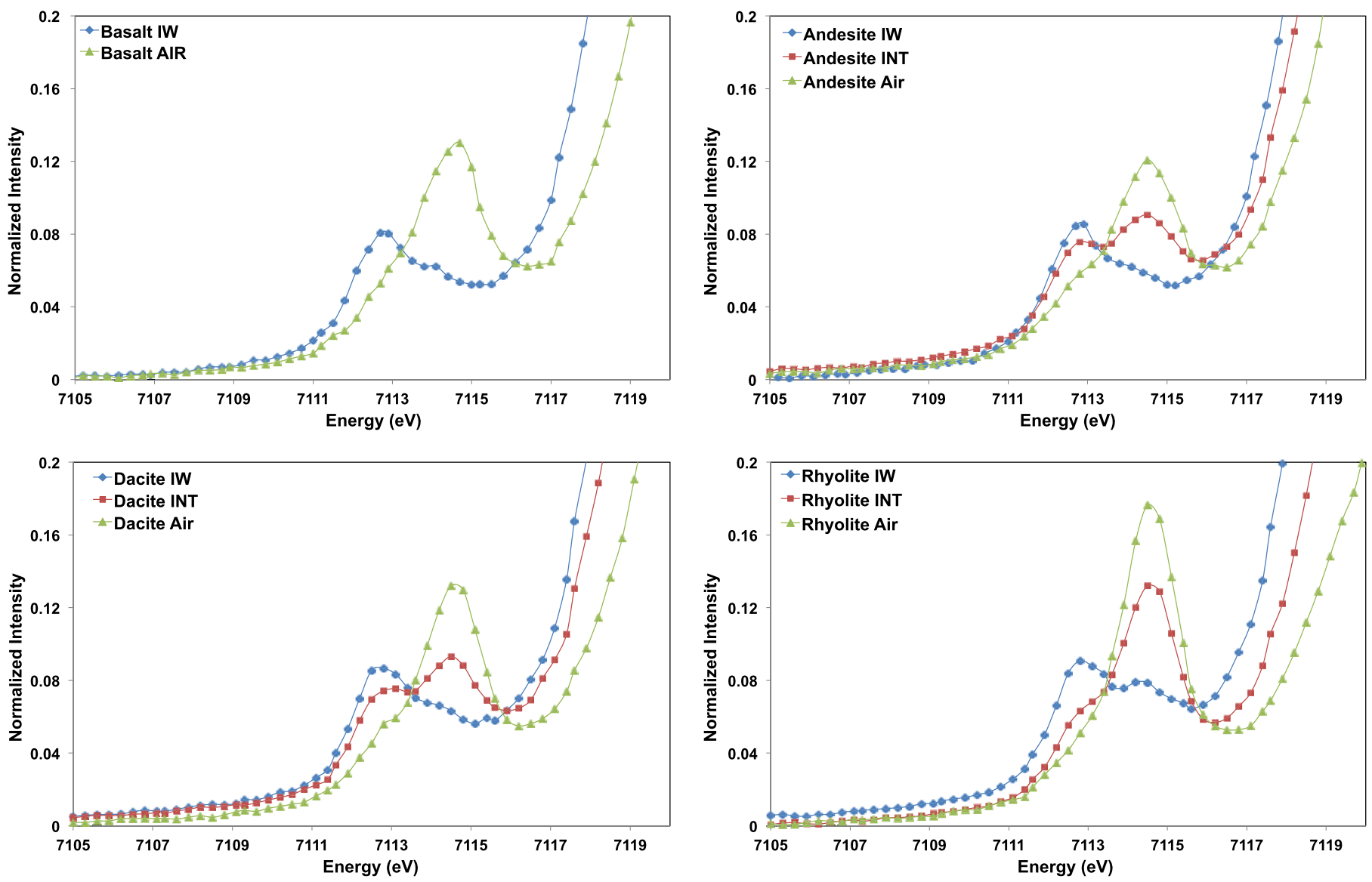

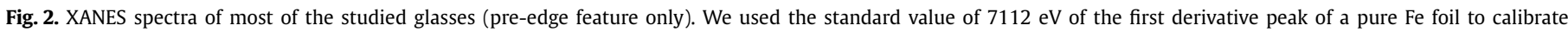

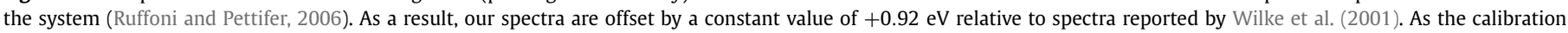

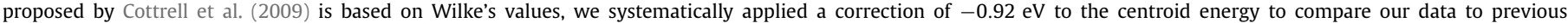
studies.

$$
\begin{aligned}
1000 \ln \beta= & 1000\left(\frac{M}{M^{*}}-1\right) \frac{1}{E_{r}}\left[\frac{R_{3}^{S}}{8 k^{2} T^{2}}-\frac{R_{5}^{S}-10 R_{2}^{S} R_{3}^{S}}{480 k^{4} T^{4}}\right. \\
& \left.+\frac{R_{7}^{S}+210\left(R_{2}^{S}\right)^{2} R_{3}^{S}-35 R_{3}^{S} R_{4}^{S}-21 R_{2}^{S} R_{5}^{S}}{20,160 k^{6} T^{6}}\right]
\end{aligned}
$$

where $M / M^{*}$ is the ratio of the masses of the isotopes considered (e.g., 56/54), $E_{r}$ is the free recoil energy (1.956 meV), $k$ is the Boltzmann constant, $T$ is the temperature in $\mathrm{K}$, and $R_{j}^{S}$ is the $j$ th moment of $S$ centered on $E_{R}$ given by

$R_{j}^{S}=\int_{-\infty}^{+\infty} S(E)\left(E-E_{R}\right)^{j} d E$.

At the high temperatures relevant to igneous geochemistry, the fractionation is well approximated by the first term in the series expansion,

$1000 \ln \beta=1000\left(\frac{M}{M^{*}}-1\right) \frac{1}{E_{r}}\left[\frac{R_{3}^{S}}{8 k^{2} T^{2}}\right]$.

We recognize the mean force constant of the bonds holding iron in position (Lipkin, 1995, 1999),

$\langle F\rangle=\frac{M}{E_{R} \hbar^{2}} R_{3}^{S}$,

which leads to a familiar formula of geochemistry (Herzfeld and Teller, 1938; Bigeleisen and Goeppert-Mayer, 1947),
$1000 \ln \beta=1000\left(\frac{1}{M^{*}}-\frac{1}{M}\right) \frac{\hbar^{2}}{8 k^{2} T^{2}}\langle F\rangle$.

For the ratio ${ }^{56} \mathrm{Fe} /{ }^{54} \mathrm{Fe}$, this equation takes the form,

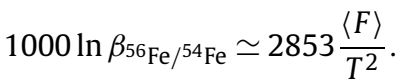

As can be seen from the equations above, calculation of iron force constant uses the third moment of the spectrum, meaning that the signal at high energy ends of the spectrum (Eq. (4)), even if weak, can become significant when it is multiplied by the energy cubed. This makes this technique highly sensitive to baseline subtraction. We have implemented several changes to the data acquisition and reduction techniques that now yield more reproducible force constant estimates. Part of these changes result from the development by our group of a stand-alone Mathematica software named SciPhon (available as electronic supplement). The main features of our approach are:

1. We perform very broad energy scans, which allows us to subtract the baseline by using a linear interpolation between the residual signals measured at the low and high energy ends of the spectrum.

2. The uncertainties in the energy scaling and baseline subtraction are now propagated in the calculation of the mean force constant, while values reported previously only incorporated uncertainties arising from counting statistics (Appendix A). 

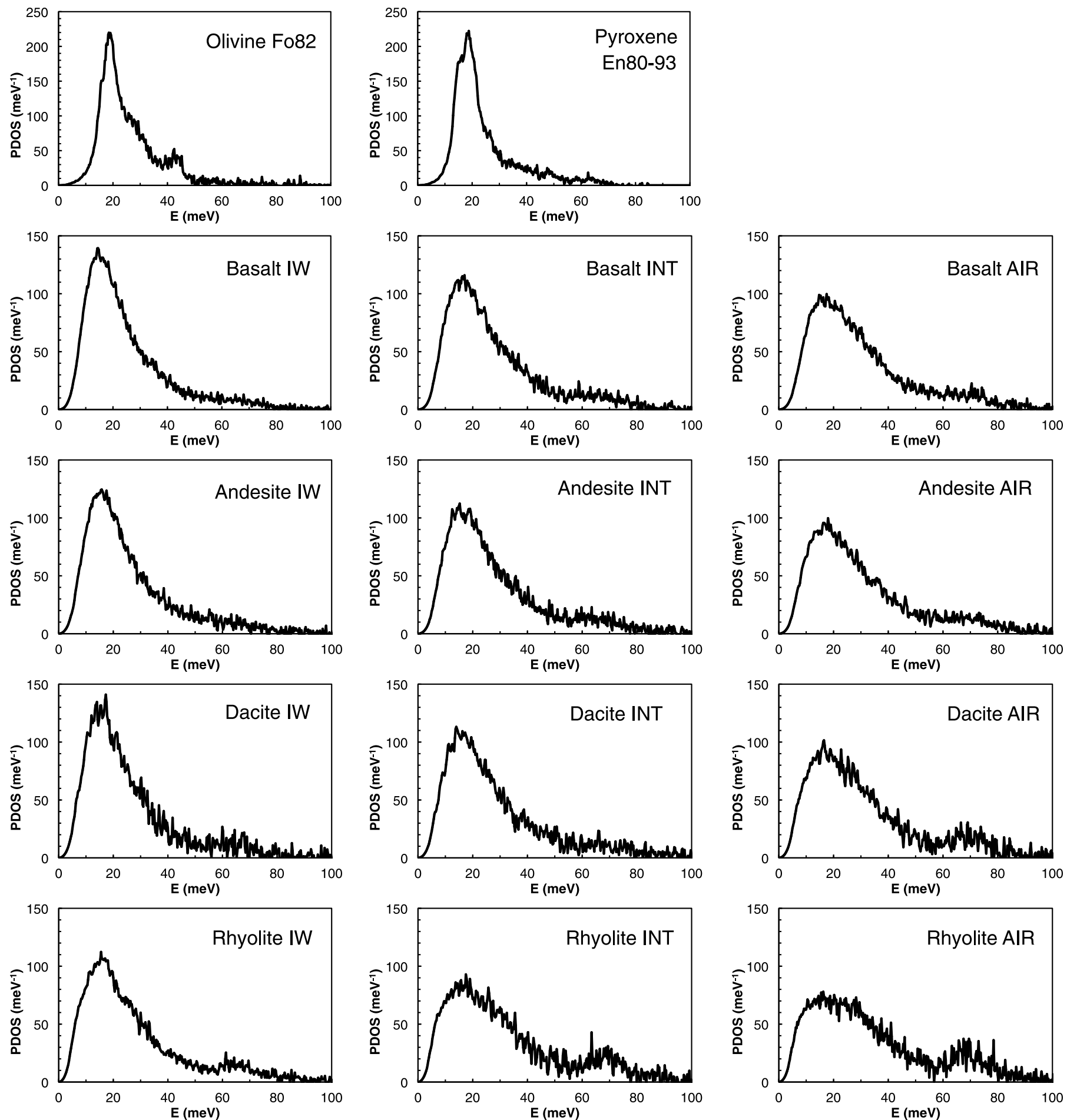

Fig. 3. Partial phonon density of states (all DOS from this study except pyroxene, which is from Jackson et al., 2009).

The glass samples were mounted in epoxy. The NRIXS measurements were done at beamline 3-ID-B of the Advanced Photon Source (APS) at Argonne National Laboratory (iron force constants are compiled in Table 1). The storage ring was operated in top-up mode with 24 bunches separated by 153 ns. One or two APD detectors were positioned a few millimeters away from the sample. The average energy resolution (full width at half maximum - FWHM) was $1.33 \mathrm{meV}$. The monochromator was tuned from $\sim-120 \mathrm{meV}$ to $\sim+130 \mathrm{meV}$ with a step size of $0.25 \mathrm{meV}$ and a collection time of $5 \mathrm{~s}$ per step. Some samples were measured over a broader energy interval extending to $+170 \mathrm{meV}$. Multiple scans $(\sim 8)$ were needed to yield high-quality data. All data were acquired at room pressure and room temperature ( $301 \pm 1 \mathrm{~K})$. Data reduction was done with a Mathematica software (SciPhon 1.0) developed by the authors. The outputs from SciPhon agree with PHOENIX (Sturhahn, 2000) when the same data are used as input. The main differences between SciPhon and PHOENIX are that SciPhon allows for streamlined linear baseline subtraction, has a GUI interface, provides the parameters needed for applications to isotope geochemistry, and propagates all sources of uncertainties. 


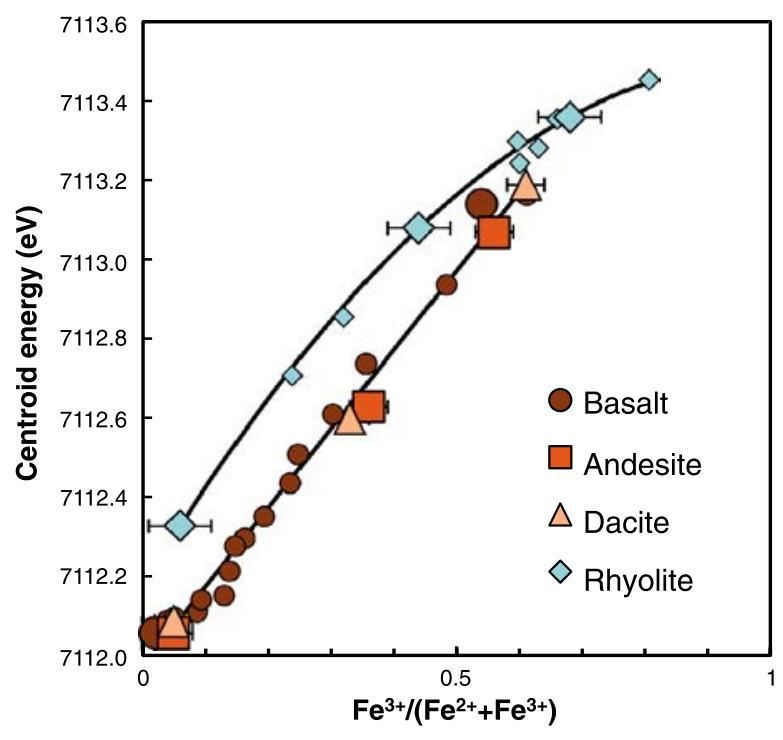

Fig. 4. Redox and structural controls on Fe K-edge XANES centroid energy $(E)$ of silicate glasses. The centroid positions of basalt, andesite, dacite, and rhyolite correlate with iron oxidation state: $\mathrm{Fe}^{3+} / \mathrm{Fe}_{\text {tot }}=0.4977(E-\mu)+0.2431$ with $\mu=7112.461 \mathrm{eV}$. Rhyolites define a different trend: $\mathrm{Fe}^{3+} / \mathrm{Fe}_{\text {tot }}=0.2900(E-$ $\mu)^{2}+0.7461(E-\mu)+0.4695$ with $\mu=7113.097 \mathrm{eV}$. These calibrations can be used to measure in situ $\mathrm{Fe}^{3+} / \mathrm{Fe}_{\text {tot }}$ ratios using XANES data. The uncertainties in $\mathrm{Fe}^{3+} / \mathrm{Fe}_{\text {tot }}$ ratio determinations associated with data regression are \pm 0.008 for basalt-andesite-dacite and \pm 0.015 for rhyolite. At high $\mathrm{Fe}^{3+} / \mathrm{Fe}_{\text {tot }}$ ratio, the two curves converge but at low $\mathrm{Fe}^{3+} / \mathrm{Fe}_{\text {tot }}$ ratio, the centroid energy of rhyolite is higher than basalt, andesite, and dacite. This suggests that a shift in $\mathrm{Fe}^{2+}$ coordination geometry occurs in rhyolitic magmas relative to basalt, andesite and dacite. The large symbols are data from Table 1 (basalt, andesite, dacite, and rhyolite) while the small symbols (basalt and rhyolite) are from Cottrell et al. (2009).

There are other, more subtle differences between the two softwares that will be detailed in a future publication.

\section{Results}

Table 1 compiles the $\mathrm{Fe}^{3+} / \mathrm{Fe}_{\text {tot }}$ ratio measured by Mössbauer, mean force constant $\langle F\rangle$ measured by NRIXS, coefficients to calculate $\beta$-factors at low temperature, major element compositions $\left(\mathrm{SiO}_{2}, \mathrm{Al}_{2} \mathrm{O}_{3}, \mathrm{FeO}, \mathrm{CaO}, \mathrm{MgO}, \mathrm{Na}_{2} \mathrm{O}, \mathrm{K}_{2} \mathrm{O}, \mathrm{TiO}_{2}\right)$ measured by electron probe, and normalized intensity and centroid energy of XANES spectra. A more extensive compilation of NRIXS data is provided in (Appendix B Table S3). It includes determinations of the temperature from the detailed balance, Lamb-Mössbauer factor, LambMössbauer factor at $T=0$, kinetic energy per atom, kinetic energy at $T=0$, internal energy per atom, mean-square displacement, $d\left\langle z^{2}\right\rangle / d T$, force constant, coefficients for calculating $\beta$-factors at low temperature, resilience, Helmholtz free energy, vibrational specific heat, vibrational entropy, critical temperature, Debye velocity, $v_{\mathrm{p}}$ and $v_{\mathrm{s}}$. Because the present paper is concerned with high temperature isotopic fractionation where $1000 \ln \beta$ scales as $1 / T^{2}$ (Eqs. (5), (6)), only the force constant given by the 3rd moment of $S(E)$ is discussed. The coefficients for calculating $\beta$-factors at temperatures below $\sim 300^{\circ} \mathrm{C}$, are compiled in Table 1 . The $\mathrm{Fe}^{3+} / \mathrm{Fe}_{\text {tot }}$ ratios measured by Mössbauer range between $\sim 0$ for those synthesized under a $f_{2}$ of IW to $\sim 0.7$ for those equilibrated in air. The $\mathrm{SiO}_{2}$ content ranges from $\sim 46$ to $76 \mathrm{wt} \%$, which spans the range of values commonly encountered in natural systems.

XANES results show correlations between centroid energy and $\mathrm{Fe}^{3+} / \mathrm{Fe}_{\text {tot }}$ ratio (Fig. 4) that are consistent with earlier results (Cottrell et al., 2009). In particular, we confirm the observation that rhyolitic glasses define a trend shifted to higher centroid energy than basalts. A new result of the present work is the finding

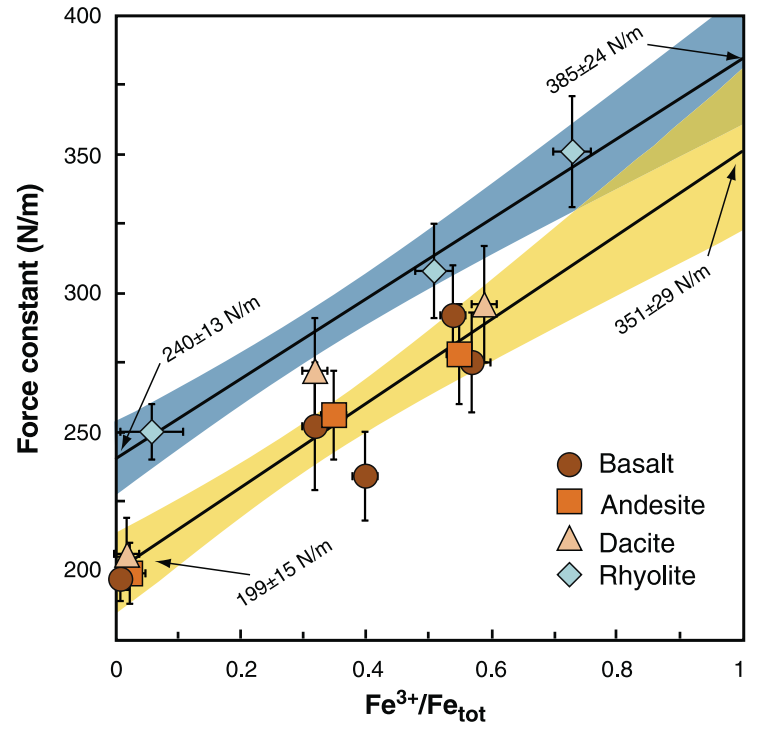

Fig. 5. Iron force constants in variably oxidized synthetic silicate glasses (Table 1). Basalt, andesite, dacite, and rhyolite glasses define linear arrays that can be extrapolated to $\mathrm{Fe}^{3+} / \mathrm{Fe}_{\text {tot }}=0$ and $\mathrm{Fe}^{3+} / \mathrm{Fe}_{\text {tot }}=1$ to estimate the force constants of $\mathrm{Fe}^{2+}$ and $\mathrm{Fe}^{3+}$, respectively. Basalt, andesite, and dacite define a single correlation that gives force constants of $199 \pm 15$ and $351 \pm 29 \mathrm{~N} / \mathrm{m}$ for the $\mathrm{Fe}^{2+}$ and $\mathrm{Fe}^{3+}$ end-members, respectively. Rhyolite defines a different correlation that gives force constants of $240 \pm 13$ and $385 \pm 24 \mathrm{~N} / \mathrm{m}$ for the $\mathrm{Fe}^{2+}$ and $\mathrm{Fe}^{3+}$ end-members, respectively. The regressions were calculated using the Isoplot software. Uncertainties are $95 \%$ confidence intervals.

that basalt, andesite and dacite all plot on the same correlation, whereas rhyolite plots off to higher centroid energies. This suggests that there is a marked structural change for $\mathrm{Fe}^{2+}$ and possibly $\mathrm{Fe}^{3+}$ at the transition between dacite and rhyolite compositions. Based on these new results, we can expand the calibration for in situ $\mathrm{Fe}^{3+} / \mathrm{Fe}_{\text {tot }}$ determination by XANES established by Cottrell et al. (2009) for basalt and rhyolite to intermediate compositions andesite and dacite,

- Basalt, andesite and dacite $\left(45<\mathrm{SiO}_{2}<65 \mathrm{wt} \%\right): \mathrm{Fe}^{3+} / \mathrm{Fe}_{\text {tot }}=$ $0.4977(E-\mu)+0.2431$ with $\mu=7112.461 \mathrm{eV}$.

- Rhyolite $\left(\mathrm{SiO}_{2} \simeq 76\right.$ wt\%): $\mathrm{Fe}^{3+} / \mathrm{Fe}_{\text {tot }}=0.2900(E-\mu)^{2}+$ $0.7461(E-\mu)+0.4695$ with $\mu=7113.097 \mathrm{eV}$.

The uncertainties in $\mathrm{Fe}^{3+} / \mathrm{Fe}_{\text {tot }}$ ratio determinations associated with data regression are \pm 0.008 for basalt-andesite-dacite and \pm 0.015 for rhyolites.

The average force constants of all measured phases correlate with the $\mathrm{Fe}^{3+} / \mathrm{Fe}_{\text {tot }}$ ratio (Fig. 5). Basalts, andesites, and dacites define a single linear correlation that can be extrapolated to pure end-members, which gives force constants of $199 \pm 15$ and $351 \pm 29 \mathrm{~N} / \mathrm{m}$ for $\mathrm{Fe}^{2+}$ and $\mathrm{Fe}^{3+}$, respectively. Rhyolites define a different linear correlation that gives force constants of $240 \pm 13$ and $385 \pm 24 \mathrm{~N} / \mathrm{m}$ for $\mathrm{Fe}^{2+}$ and $\mathrm{Fe}^{3+}$, respectively. The force constants of $\mathrm{Fe}^{3+}$ in basalt, andesite, dacite, and rhyolite are very similar. The force constant of $\mathrm{Fe}^{2+}$ in olivine, $197 \pm 10 \mathrm{~N} / \mathrm{m}$, is close to that of $\mathrm{Fe}^{2+}$ in basalt, andesite and dacite (Table 1) and is similar to values measured previously by NRIXS in pyroxene (orthoenstatite, 165 to $195 \mathrm{~N} / \mathrm{m}$; Jackson et al., 2009). These values are higher than those that can be derived from Mössbauer spectroscopy by recognizing that the first term in the expansion of the $\beta$-factor is $2853\langle F\rangle / T^{2}$ (Dauphas et al., 2012), which gives approximate force constants of 131,108 , and $120 \mathrm{~N} / \mathrm{m}$ for olivine, hedenbergite, and enstatite, respectively (Polyakov and $\mathrm{Mi}-$ neev, 2000). NRIXS data are used hereafter because they are less susceptible to systematic errors than conventional Mössbauer for 
application to Fe isotope geochemistry (Polyakov et al., 2007; Dauphas et al., 2012).

The mean force constant can be calculated either by taking the third centered moment of $S(E)$ or the second moment of the PDOS $g(E)$ (Lipkin, 1995). Dauphas et al. (2012) and Hu et al. (2013) showed that the two estimates are indeed mathematically equivalent and established general relationships between the moments of $S$ and $g$,

$\langle F\rangle=\frac{M}{E_{R} \hbar^{2}} \int_{-\infty}^{+\infty}\left(E-E_{R}\right)^{3} S(E) d E=\frac{M}{\hbar^{2}} \int_{0}^{+\infty} E^{2} g(E) d E$.

The force constants estimated from $g(E)$ are compiled in Table S3 of Appendix B and the PDOS are displayed in Fig. 3. The force constants from $g(E)$ are in good agreement with those from $S(E)$.

To evaluate how well NRIXS force constant measurements can predict equilibrium iron isotopic fractionation factors, we compare in Fig. 6 the predictions from force constant measurements with experimental determinations for the systems molten FeS-rhyolite (Schuessler et al., 2007), silicate-metal (Poitrasson et al., 2009; Hin et al., 2012; Jordan and Young, 2014; Shahar et al., 2013), and magnetite-olivine (Shahar et al., 2008). For molten FeS-rhyolite, the force constants used are $97 \mathrm{~N} / \mathrm{m}$ for troilite (Krawczynski et al., 2014) and $330 \pm 16 \mathrm{~N} / \mathrm{m}$ for rhyolitic glass with $38 \% \mathrm{Fe}^{2+}-62 \%$ $\mathrm{Fe}^{3+}$ (Fig. 5). For molten silicate-metal, the force constants used are $199 \pm 15 \mathrm{~N} / \mathrm{m}$ for $\mathrm{Fe}^{2+}$-basaltic glass (Fig. 5) and $175 \pm 2$ and $147 \mathrm{~N} / \mathrm{m}$ for fcc and bcc iron, respectively (Dauphas et al., 2012; Krawczynski et al., 2014). For magnetite-olivine, the force constants used are $230 \pm 6 \mathrm{~N} / \mathrm{m}$ for magnetite (Dauphas et al., 2012) and $197 \pm 10 \mathrm{~N} / \mathrm{m}$ for olivine Fo82 (Table 1). Polyakov et al. (2007) also reported a force constant of $\sim 228 \mathrm{~N} / \mathrm{m}$ for magnetite using data previously published by Seto et al. (2003).

Despite the fact that the experimental determinations were made mostly on molten phases and the force constant measurements by NRIXS were made on solid phases, there is good agreement between the two approaches for the two systems. The two approaches disagree for magnetite-olivine, where the predictions from force constant measurements are smaller than experimentally determined values. This could be due to the fact that the force constant determination for magnetite is too low because it was measured over a too narrow energy range $(-80$ to $+80 \mathrm{meV})$, so this force constant should be re-measured.

\section{Discussion}

\subsection{Oceanic basalts (MORBs)}

The force constants measured here provide a basis for estimating equilibrium iron isotope fractionation. Indeed, knowing the $\beta$-factors of two phases $\mathrm{A}$ and $\mathrm{B}$, it is straightforward to calculate the equilibrium fractionation as

$\delta_{B}-\delta_{A}=1000 \ln \beta_{B}-1000 \ln \beta_{A}=2853 \frac{\langle F\rangle_{B}-\langle F\rangle_{A}}{T^{2}}$.

In particular, we can evaluate whether partial melting of Earth's upper-mantle to create oceanic crust (i.e., mid-ocean ridge basalts; MORBs) can induce isotopic fractionation and explain the heavy Fe isotopic composition of most oceanic basalts relative to abyssal peridotites and chondrites (Craddock and Dauphas, 2011; Craddock et al., 2013; Teng et al., 2013). The force constants of $\mathrm{Fe}^{2+}$ and $\mathrm{Fe}^{3+}$ in mantle minerals are uncertain. As a first order estimate, we take those values to be $197 \pm 10 \mathrm{~N} / \mathrm{m}$ (olivine Fo82, Table 1) and $255 \pm 24 \mathrm{~N} / \mathrm{m}$ (Fig. S1 of Appendix B). The calculated $\mathrm{Fe}$ isotopic fractionation is little sensitive to the force constant of $\mathrm{Fe}^{3+}$ in minerals because $\mathrm{Fe}^{3+}$ behaves as
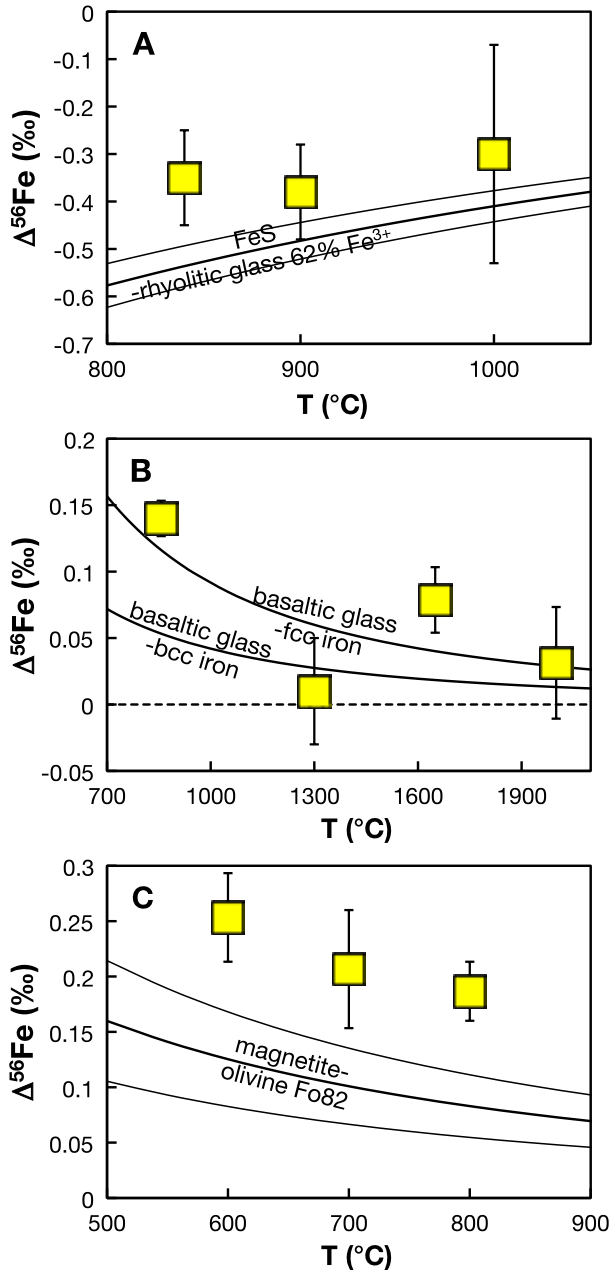

Fig. 6. Comparison between predicted and measured equilibrium fractionation factors for the systems molten FeS-rhyolite (A) molten silicate-metal (B), and magnetite-olivine $(C)$. The data points in panel $A$ are experimental estimates of equilibrium iron isotopic fractionations between pyrrhotite and peralkaline rhyolitic melt containing 38\% $\mathrm{Fe}^{2+}-62 \% \mathrm{Fe}^{3+}$ (Schuessler et al., 2007). The predicted values were calculated using Eq. (6) and the force constants of troilite $(97 \mathrm{~N} / \mathrm{m})$ from Krawczynski et al. (2014) and that of rhyolitic melt with $38 \% \mathrm{Fe}^{2+}-62 \% \mathrm{Fe}^{3+}$ from this study $(330 \pm 16 \mathrm{~N} / \mathrm{m}$; Fig. 5). The data points in panel B are experimental estimates of equilibrium iron isotopic fractionations between silicate and metallic liquids (Poitrasson et al., 2009; Hin et al., 2012; Jordan and Young, 2014; Shahar et al., 2013). The predicted values were calculated using the force constants of $\mathrm{Fe}^{2+}$-basaltic glass $(199 \pm 15 \mathrm{~N} / \mathrm{m}$; Fig. 5) and those of fcc and bcc iron $(175 \pm 2$ and $147 \mathrm{~N} / \mathrm{m}$, respectively; Dauphas et al., 2012; Krawczynski et al., 2014). The data points in panel $\mathrm{C}$ are experimental estimates of equilibrium iron isotopic fractionation between magnetite and fayalite (Shahar et al., 2008). The predicted values were calculated using the force constants of magnetite $(230 \pm 6 \mathrm{~N} / \mathrm{m}$, Polyakov et al., 2007; Dauphas et al., 2012) and that of olivine Fo82 (197 $\pm 10 \mathrm{~N} / \mathrm{m}$, Table 1). Note that the force constant values reported by Dauphas et al. (2012) and Polyakov et al. (2007) may be underestimated because the energy range may have been too narrow (from -80 to $+80 \mathrm{meV}$ ) and some signal may be missing, which could explain the discrepancy between the data and NRIXS predictions. The thin lines in panels $A$ and $C$ are confidence intervals for the predictions from NRIXS.

a moderately incompatible element $\left(K_{\mathrm{d}}=C_{\text {melt }} / C_{\text {solid }} \approx 4.5\right.$; Canil et al., 1994; Mallmann and O'Neill, 2009; Cottrell and Kelley, 2011) and partitions into the melt even at relatively low degree partial melting. Thus, $\mathrm{Fe}^{3+}$ in minerals plays a minor role in the isotopic mass-balance. On the other hand, small changes in the force constant of $\mathrm{Fe}^{2+}$ in minerals and melts can greatly modify the predicted isotopic fractionation between mantle minerals and melts. Keeping other parameters constant, each $10 \mathrm{~N} / \mathrm{m}$ change in the force constant of either $\mathrm{Fe}^{2+}$ in melt or minerals changes the net isotopic shift by $\sim 0.01 \%$ for $\delta^{56} \mathrm{Fe}$. The temperature at depth during melting of the MORB source is taken 
to be $\sim 1300^{\circ} \mathrm{C}$ (McKenzie and Bickle, 1988). At such a temperature, the force constants given above translate into equilibrium iron isotopic fractionations in $\delta^{56} \mathrm{Fe}$ of $+0.18 \pm 0.04 \%$ between melt $\mathrm{Fe}^{3+}$ and $\mathrm{Fe}^{2+},+0.07 \pm 0.03 \%$ between solid $\mathrm{Fe}^{3+}$ and $\mathrm{Fe}^{2+}$, and $0.00 \pm 0.02 \%$ between melt $\mathrm{Fe}^{2+}$ and solid $\mathrm{Fe}^{2+}$. Our results thus demonstrate that significant equilibrium Fe isotopic fractionation between $\mathrm{Fe}^{2+}$ and $\mathrm{Fe}^{3+}$ is present at mantle temperatures. This fractionation is an order of magnitude larger than the precision routinely achievable by multi-collector inductively coupled plasma mass spectrometry (Dauphas et al., 2009a, 2009b; Millet et al., 2012). The predicted small isotopic fractionation between $\mathrm{Fe}^{2+}$ in basaltic melt and $\mathrm{Fe}^{2+}$ in olivine or pyroxene is consistent with minimal isotopic fractionation relative to chondrites (Craddock and Dauphas, 2011) measured in basalts from the HED meteorite parent-body Vesta and the SNC meteorite parent body Mars (Poitrasson et al., 2004; Weyer et al., 2005; Wang et al., 2012), where $\mathrm{Fe}^{2+}$ dominates.

With our results, we assess quantitatively whether equilibrium isotopic fractionation between $\mathrm{Fe}^{2+}$ and $\mathrm{Fe}^{3+}$ can explain the heavy iron isotopic fractionation on MORBs $\left(\delta^{56} \mathrm{Fe} \approx+0.105 \pm\right.$ $0.006 \%$, Teng et al., 2013) relative to their source $\left(\delta^{56} \mathrm{Fe}=\right.$ $+0.025 \pm 0.025 \%$, Craddock et al., 2013). During partial melting, $\mathrm{Fe}^{2+}$ has a melt/solid partition coefficient of $\sim 1$, while $\mathrm{Fe}^{3+}$ has a partition coefficient of $\sim 4.5$ and behaves as a moderately incompatible element (Canil et al., 1994; Mallmann and O'Neill, 2009; Cottrell and Kelley, 2011). MORBs are produced by 6 to 20\% nearfractional melting (we adopt a value of $10 \%$; Klein and Langmuir; 1987). MORBs have a variable $\mathrm{Fe}^{3+} / \mathrm{Fe}_{\text {tot }}$ ratio (from $\sim 0.13$ to $\sim 0.16$ ) with the most enriched samples being the most reduced, which was interpreted to reflect reduction of $\mathrm{Fe}^{3+}$ to $\mathrm{Fe}^{2+}$ by recycled organic carbon (Cottrell and Kelley, 2013). In the following, we adopt a value of $\sim 0.16$ (Cottrell and Kelley, 2011), which corresponds to a $\mathrm{Fe}^{3+} / \mathrm{Fe}_{\text {tot }}$ ratio of $\sim 0.042$ in the source of MORBS before melting, calculated by using the partition coefficients and degree of partial melting given above (Eq. (S18) of Appendix B). This ratio is close to the value measured in fertile mantle peridotites (Canil et al., 1994). With the set of equilibrium iron isotopic fractionation factors calculated above, we estimate that MORBs should have $\delta^{56} \mathrm{Fe}$ values that are fractionated by $+0.023 \pm 0.020 \%$ relative to the source mantle (Fig. 7, fractional melting model Eqs. (S35) and (S37) of Appendix B). The model results in Fig. 7 are insensitive to assumptions regarding the $\mathrm{Fe}^{3+} / \mathrm{Fe}_{\text {tot }}$ ratio of the source, the mode of melting (batch or fractional), and the partition coefficient of $\mathrm{Fe}^{3+}$ because $\delta^{56} \mathrm{Fe}$ is plotted as a function of the melt $\mathrm{Fe}^{3+} / \mathrm{Fe}_{\text {tot }}$ ratio and this parameter largely controls the isotopic mass-balance. The predicted melt $\mathrm{Fe}^{3+} / \mathrm{Fe}_{\text {tot }}$ ratio varies little from 0.134 to 0.175 over 5 to $20 \%$ partial melting. We recognize that this model is simplistic in the sense that it does not take into account the possibility that the redox state of iron in the melt may have been partially buffered, which is suggested by the lack of correlation between $\mathrm{Fe}^{3+} / \mathrm{Fe}_{\text {tot }}$ and degree of partial melting (Bezos and Humler, 2005; Cottrell and Kelley, 2011). Nevertheless, given other sources of errors, this model is sufficient as a first pass on this question.

Our NRIXS results predict that mantle partial melts should be enriched in the heavy isotopes of iron relative to the source and we are able to explain $\sim 1 / 3$ of the isotopic fractionation between MORBs and mantle peridotites $\left(\delta^{56} \mathrm{Fe}_{\mathrm{MORB}}-\delta^{56} \mathrm{Fe}_{\text {mantle }} \approx\right.$ $+0.08 \pm 0.03 \%$ ). Although our study cannot explain the whole extent of the fractionation measured in MORBs relative to peridotites, several additional factors not considered in this work probably influence this fractionation. An important one is that the glasses studied are only proxies for melts, and structural relaxation during cooling between the liquidus and the glass transition could potentially affect reduced partition function ratios for iron isotopes. Furthermore, the $\beta$ values are extrapolated to magmatic

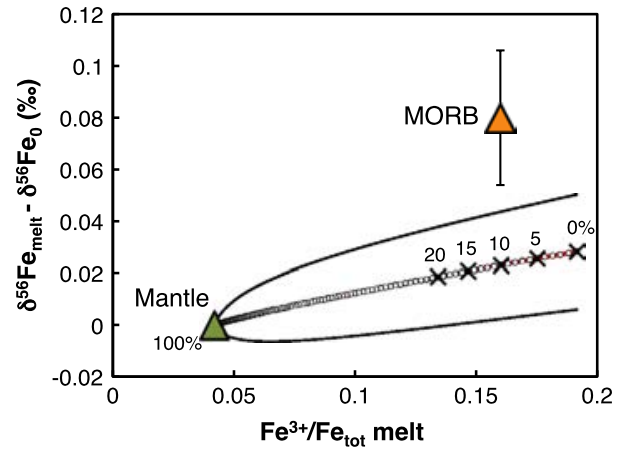

Fig. 7. Iron isotopic and redox evolution during mantle melting to form MORBs. MORBs (orange triangle) have $\mathrm{Fe}^{3+} / \mathrm{Fe}_{\text {tot }}=0.16$ (Cottrell and Kelley, 2011) and $\delta^{56} \mathrm{Fe}_{\mathrm{MORB}}-\delta^{56} \mathrm{Fe}_{\text {mantle }}=+0.08 \pm 0.03 \%$ (Weyer and Ionov, 2007; Teng et al., 2013; Craddock et al., 2013). The mantle $\mathrm{Fe}^{3+} / \mathrm{Fe}_{\text {tot }}$ ratio (0.043; green triangle) was adjusted to reproduce the $\mathrm{Fe}^{3+} / \mathrm{Fe}_{\text {tot }}$ of MORBs at $10 \%$ partial melting (Klein and Langmuir, 1987) using liquid/solid partition coefficients of 1 and 4.5 for $\mathrm{Fe}^{2+}$ and $\mathrm{Fe}^{3+}$, respectively (Canil et al., 1994; Mallmann and O'Neill, 2009; Cottrell and Kelley, 2011). The plotted curve (red with open circles) is calculated based on a model of fractional melting (Eq. (S18) of Appendix B for $\mathrm{Fe}^{3+} / \mathrm{Fe}_{\text {tot }}$ and Eqs. (S35), (S37) of Appendix $\mathrm{B}$ for $\delta^{56} \mathrm{Fe}$ ) but batch melting gives identical results. Using different parameters for the mantle $\mathrm{Fe}^{3+} / \mathrm{Fe}_{\text {tot }}$ ratio and partition coefficients of $\mathrm{Fe}^{2+}$ and $\mathrm{Fe}^{3+}$ would also not change the results provided that those parameters reproduce the MORB $\mathrm{Fe}^{3+} / \mathrm{Fe}_{\text {tot }}$ ratio of 0.16 at $10 \%$ partial melting. The black curves represent the $95 \%$ confidence interval of model predictions. The percentages are degrees of partial melting. (For interpretation of the references to color in this figure legend, the reader is referred to the web version of this article.)

temperatures from measurements of force constants at room temperature by assuming harmonic behavior (Eq. (1)), which may not be valid. Pressure is another parameter to consider as the coordination environments of network forming elements such as silicon and aluminum in silicate glasses and melts can change with pressure (Wolf and McMillan, 1995). The coordination environment of Fe in silicate melts could also differ at the pressures relevant to MORB formation ( $\sim 1$ to $3 \mathrm{GPa})$ compared to surface conditions (Mysen and Virgo, 1985; Waychunas et al., 1988; Brearly, 1990). Further work is therefore needed to assess these effects on melt-mineral equilibrium isotopic fractionation during partial melting to form MORBs. Finally, a difficulty with direct $\mathrm{Fe}^{3+} / \mathrm{Fe}_{\text {tot }}$ determinations is that this ratio can be modified by degassing, charge-transfer reaction between multi-valence species, and alteration. Mallmann and O'Neill (2013) tried to address this issue by measuring $\mathrm{V}$ partitioning between melt and early-formed olivine to estimate the $\mathrm{fO}_{2}$ of basalts. From these estimates, they calculated $\mathrm{Fe}^{3+} / \mathrm{Fe}_{\text {tot }}$ ratios that are higher by 0.09 on average than XANES data. The reason for this discrepancy is unknown but a higher $\mathrm{Fe}^{3+} / \mathrm{Fe}_{\text {tot }}$ ratio in MORBs would produce larger Fe isotopic fractionation.

Terrestrial basalts are not the only planetary magmas that show heavy Fe isotopic composition. Indeed, angrites also have $\delta^{56} \mathrm{Fe}$ that averages $+0.12 \pm 0.01 \%$ (Wang et al., 2012), which is very close to the mean value of MORBs of $\delta^{56} \mathrm{Fe}=+0.105 \pm 0.006 \%$ (Teng et al., 2013). The angrite parent-body is relatively oxidized (IW + 1 to IW + 2; McKay et al., 1994; Jurewicz et al., 1991, 1993) but not sufficiently so as to stabilize $\mathrm{Fe}^{3+}$ in significant quantities. Therefore, equilibrium isotopic fractionation between $\mathrm{Fe}^{2+}$ and $\mathrm{Fe}^{3+}$ is unlikely to be responsible for the high $\delta^{56} \mathrm{Fe}$ value of angrites and other processes have to be considered, such as kinetic or equilibrium isotopic fractionation during vaporization, core formation, or magma differentiation. The range of options for Earth is more limited because measurements of mantle peridotites point to a near-chondritic Fe isotopic composition for the silicate Earth (Weyer and Ionov, 2007; Craddock et al., 2013), thus implicating partial melting as the cause of Fe isotopic fractionation. 


\subsection{Granitoids and rhyolites}

The calculated iron isotopic fractionation between basalt and mantle peridotite arises entirely from differences in mean force constants between $\mathrm{Fe}^{2+}$ and $\mathrm{Fe}^{3+}$. As shown below, Fe isotope fractionation can also be controlled by coordination environments. This is readily seen in the deviation of the trend $\langle F\rangle$ vs. $\mathrm{Fe}^{2+} / \mathrm{Fe}_{\text {tot }}$ for rhyolites when compared to the less silicic glasses (Fig. 5). The reason for this jump in force constant of $\mathrm{Fe}^{2+}$ between dacite and rhyolite is unknown. Iron K-edge X-ray absorption fine structure (XAFS) spectroscopy shows that in basaltic glasses, $\mathrm{Fe}^{2+}$ and $\mathrm{Fe}^{3+}$ are in 5-fold average coordination (Wilke et al., 2005; Jackson et al., 2005). Rhyolitic glasses have been less studied but available results suggest that $\mathrm{Fe}^{2+}$ is in 4- to 5-fold average coordination while the average coordination of $\mathrm{Fe}^{3+}$ depends on the melt composition and ranges between 4 and 5 (Métrich et al., 2006; Giuli et al., 2012). Thus, based on published reports, there does not appear to be a major change in $\mathrm{Fe}^{2+}$ coordination number between basalt and rhyolite. To investigate this issue further, we have acquired iron K-edge X-ray Absorption Near Edge Structure (XANES) spectra of the silicate glasses investigated here (Fig. 2). Cottrell et al. (2009) had found that at a given $\mathrm{Fe}^{3+} / \mathrm{Fe}_{\text {tot }}$ ratio, the centroid energy of the XANES peak was shifted to higher values in rhyolite relative to basalt, which they interpreted to reflect a change in the coordination environment of iron. Our measurements are in good agreement with those earlier results (Fig. 4). However, compositions intermediate between basalt and rhyolite had not been studied previously. Our results show that basalt, andesite, and dacite define a single trend in centroid energy vs. $\mathrm{Fe}^{3+} / \mathrm{Fe}_{\text {tot }}$ while rhyolite is shifted to higher values. At high $\mathrm{Fe}^{3+} / \mathrm{Fe}_{\text {tot }}$ ratios, the two trends seem to converge. These observations confirm the conclusions based on NRIXS measurements that the coordination environment of $\mathrm{Fe}^{2+}$ is different in rhyolite compared with less silicic magmas.

The determination of iron $\beta$-factors in felsic melts can also help understand what processes control iron isotopic fractionation during continental crust differentiation. It is well documented that granitoids and rhyolites with high $\mathrm{SiO}_{2}$ content (>70 wt\%) tend to have heavy iron isotopic compositions (Poitrasson and Freydier, 2005; Heimann et al., 2008; Telus et al., 2012). Several interpretations have been put forward to explain this feature including (i) isotopic fractionation induced by Soret diffusion (Lundstrom, 2009), (ii) removal of isotopically light iron by exsolved fluids during the late stages of magmatic evolution (Poitrasson and Freydier, 2005; Heimann et al., 2008; Telus et al., 2012), or (iii) fractional crystallization (Telus et al., 2012; Sossi et al., 2012). The prospect of tracing fluid exsolution in felsic rocks using iron isotopes is exciting because these exsolved fluids are often rich in chlorine and can scavenge base metals from plutons to produce economical mineral deposits in the country rocks (e.g., porphyry copper deposits). Schuessler et al. (2009) and Telus et al. (2012) evaluated the fluid exsolution hypothesis by measuring $\mathrm{Li}$ and $\mathrm{Zn}$ isotopes in the same rocks that were measured for Fe. Telus et al. (2012) concluded that the Fe isotopic compositions of pegmatites and possibly some granitoids were affected by fluid exsolution but that for the majority granitoids and rhyolites, fractional crystallization remained a viable interpretation. Another difficulty with the fluid exsolution hypothesis is that the granitoids that have the highest $\delta^{56} \mathrm{Fe}$ values are derived from relatively anhydrous (A-type) melts (Telus et al., 2012; Sossi et al., 2012). With the new set of equilibrium fractionation factors reported in Table 1 , we evaluate quantitatively the degree to which differentiation of silicic magmas can fractionate Fe isotopes.

A difficulty with the fractional crystallization model to explain the heavy iron isotopic composition of silica-rich granitoids has always been that some of the last phases to crystallize are

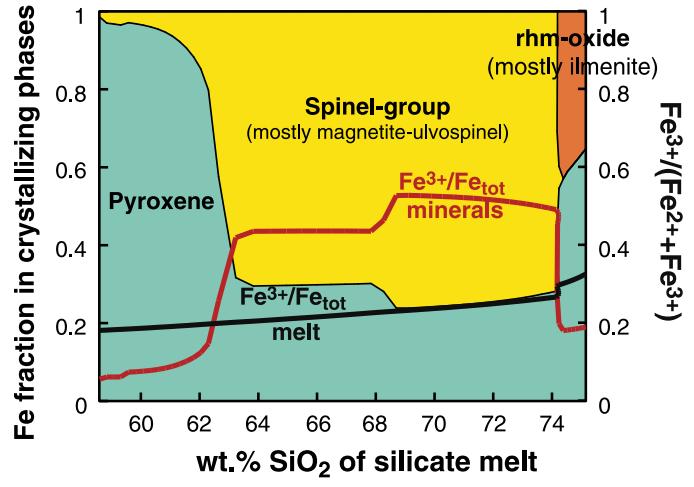

Fig. 8. Mineralogical and redox controls on iron during fractional crystallization of an andesite. This diagram gives the fractions of iron in the different minerals that crystallize at each increment of crystallization (i.e., each step of temperature drop). This calculation was performed using rhyolite-MELTS (Gualda et al., 2012) under buffered $\mathrm{fO}_{2}(\mathrm{QFM})$, so the $\mathrm{Fe}^{3+} / \mathrm{Fe}_{\text {tot }}$ of the melt does not change much during crystallization. In a system with non-buffered oxygen fugacity, the crystallization of $\mathrm{Fe}^{2+}$-rich pyroxenes would increase the $\mathrm{Fe}^{3+} / \mathrm{Fe}^{2+}$ ratio in the melt more rapidly than is does in a buffered system, leading to earlier crystallization of $\mathrm{Fe}^{3+}$-bearing oxides. This would not dramatically affect the conclusions presented here.

$\mathrm{Fe}^{3+}$-rich oxides such as magnetite (Fig. 8), which are expected to have heavy iron isotopic compositions (Shahar et al., 2008; Polyakov et al., 2007; Dauphas et al., 2012) and may drive the remaining magma towards low $\delta^{56} \mathrm{Fe}$ values, opposite to observations. Our measurements of the force constant of Fe in geologically relevant glasses can resolve this contradiction (Fig. 9). Up to dacite $\left(64 \mathrm{wt} \% \mathrm{SiO}_{2}\right)$, the force constants of $\mathrm{Fe}^{2+}$ of silicate glasses $\left(\sim 199 \mathrm{~N} / \mathrm{m}\right.$, Fig. 5) are similar to those of $\mathrm{Fe}^{2+}$ in silicate and oxide minerals (Fig. S1 of Appendix B). A shift appears with rhyolite $\left(76 \mathrm{wt} \% \mathrm{SiO}_{2}\right)$, for which the $\mathrm{Fe}^{2+}$ force constant $(\sim 240 \mathrm{~N} / \mathrm{m})$ is higher than that in basalt, andesite, or dacite, most likely reflecting a change in the coordination environment of $\mathrm{Fe}^{2+}$. For convenience, we use $\mathrm{SiO}_{2}$ as the explanatory variable in Fig. 9 but this does not mean that $\mathrm{SiO}_{2}$ is the melt component that controls iron coordination (e.g., alkalis may play a role; Sossi et al., 2012 and references therein). The force constant of $\mathrm{Fe}^{3+}$ in glasses $(\sim 370 \mathrm{~N} / \mathrm{m}$, Fig. 6) is also much higher than that in oxides ( $255 \mathrm{~N} / \mathrm{m}$; Fig. $\mathrm{S} 1$ of Appendix B). The fact that the force constants of both $\mathrm{Fe}^{2+}$ and $\mathrm{Fe}^{3+}$ in silicic magmas are higher than those encountered in silicate and oxide minerals will impart significant equilibrium isotopic fractionation between melt and crystals, which will drive the Fe isotopic composition of the magmas towards high $\delta^{56} \mathrm{Fe}$ values.

To test this idea quantitatively, we have used the software Rhyolite MELTS (Gualda et al., 2012) to model the fractional crystallization and attendant iron isotopic evolution of an andesitic composition to produce a rhyolitic magma at a constant oxygen fugacity of QFM (Fig. 8). The chemical composition of the starting andesite was in wt\% $\mathrm{SiO}_{2} 58.23, \mathrm{TiO}_{2} \quad 0.94, \mathrm{Al}_{2} \mathrm{O}_{3} \quad 16.94, \mathrm{Cr}_{2} \mathrm{O}_{3} 0.03$, $\mathrm{FeO} 7.31, \mathrm{MgO} 3.99, \mathrm{CaO} 7.08, \mathrm{Na}_{2} \mathrm{O} 3.47, \mathrm{~K}_{2} \mathrm{O}$ 1.57, $\mathrm{P}_{2} \mathrm{O}_{5} 0.24, \mathrm{H}_{2} \mathrm{O}$ 0.20 . The pressure remained constant at 1 kbar. The temperature decreased from the liquidus temperature of $1176.95^{\circ} \mathrm{C}$ to $851.95^{\circ} \mathrm{C}$ in increments of $5^{\circ} \mathrm{C}$. These conditions are appropriate to model the formation of an A-type granite (Clemens et al., 1986). The program calculates at each step the nature and abundance of minerals that are removed from the system. The iron isotopic evolution is simulated by calculating, at each step, the isotopic fractionation between the minerals removed and the remaining magma. The force constant of $\mathrm{Fe}^{2+}$ in melts evolves with $\mathrm{SiO}_{2}$ content along a parametric fit to the data (sigmoid shown in Fig. 9A; from $\sim 199$ $\mathrm{N} / \mathrm{m}$ for $\mathrm{SiO}_{2}<65 \mathrm{wt} \%$ to $\sim 240 \mathrm{~N} / \mathrm{m}$ for $\mathrm{SiO}_{2}>75 \mathrm{wt} \%$ ) while that of $\mathrm{Fe}^{3+}$ remains constant at $351 \mathrm{~N} / \mathrm{m}$ (Fig. 5). In silicates and oxide minerals, the force constant of $\mathrm{Fe}^{2+}$ is taken to be $197 \mathrm{~N} / \mathrm{m}$ (i.e., identical to olivine, Table 1) while that of $\mathrm{Fe}^{3+}$ is $255 \mathrm{~N} / \mathrm{m}$ (Fig. S1 of Appendix B). The modeled evolution of the melt repro- 

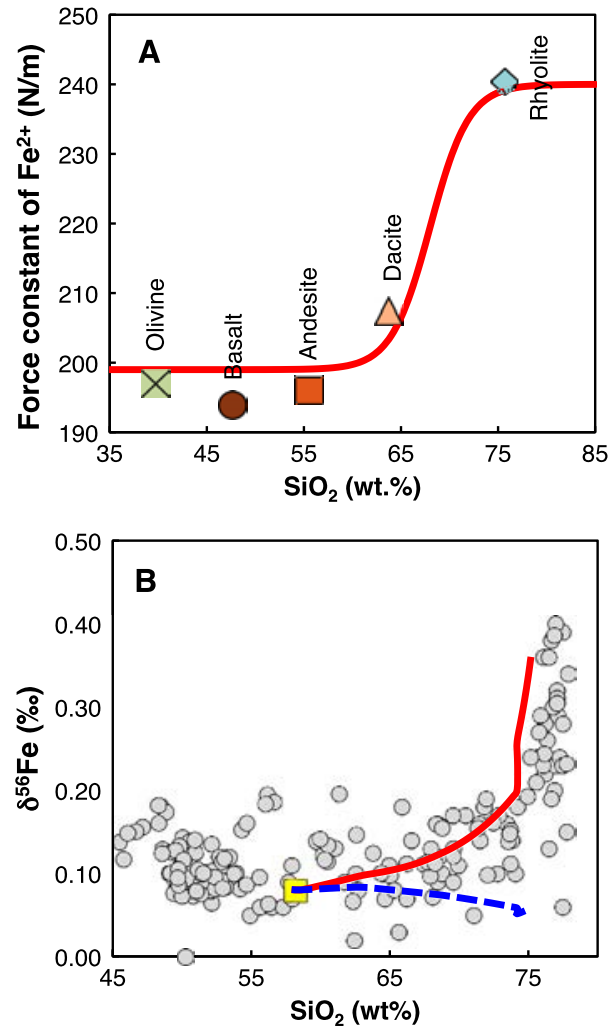

Fig. 9. Control on iron isotopic fractionation in silicic magmas. A. Force constants of $\mathrm{Fe}^{2+}$ in olivine $(197 \mathrm{~N} / \mathrm{m})$, basalt $(194 \mathrm{~N} / \mathrm{m})$, andesite $(196 \mathrm{~N} / \mathrm{m})$, dacite $(207 \mathrm{~N} / \mathrm{m})$, rhyolite $(240 \mathrm{~N} / \mathrm{m})$. The symbols for synthetic glasses are identical to Fig. 1. The continuous red curve is a fit to the data using a sigmoid function $\langle F\rangle=199+41 /\left(1+e^{34-\mathrm{SiO}_{2} / 2}\right)$ in $\mathrm{N} / \mathrm{m}$. B. Modeled Fe isotopic fractionation of silicic magmas during differentiation. The gray circles are measured $\delta^{56} \mathrm{Fe}$ values of terrestrial magmatic rocks. The curves are model predictions using the rhyoliteMELTS software assuming fractional crystallization of an andesitic melt (in wt\%, $\mathrm{SiO}_{2}=58.23, \mathrm{TiO}_{2}=0.94, \mathrm{Al}_{2} \mathrm{O}_{3}=16.94, \mathrm{Cr}_{2} \mathrm{O}_{3}=0.03, \mathrm{FeO}=7.31, \mathrm{MgO}=$ $\left.3.99, \mathrm{CaO}=7.08, \mathrm{Na}_{2} \mathrm{O}=3.47, \mathrm{~K}_{2} \mathrm{O}=1.57, \mathrm{P}_{2} \mathrm{O}_{5}=0.24, \mathrm{H}_{2} \mathrm{O}=0.20\right)$ at $\mathrm{P}=1 \mathrm{~kb}$ and $\mathrm{fO}_{2}=\mathrm{FMQ}$. The temperature in the calculation decreases from the liquidus of $1177^{\circ} \mathrm{C}$ to $852^{\circ} \mathrm{C}$ in increments of $5^{\circ} \mathrm{C}$. At each step, isotopic fractionation between residual melt and crystallizing minerals is calculated using the relevant force constants. For $\mathrm{Fe}^{2+}$ and $\mathrm{Fe}^{3+}$ in silicate and oxide minerals, we use force constants of $197 \mathrm{~N} / \mathrm{m}$ (olivine) and $255 \mathrm{~N} / \mathrm{m}$ (Fig. S1 of Appendix B), respectively. For $\mathrm{Fe}^{2+}$ in melt, we use the sigmoid function in panel $\mathrm{A}$. For $\mathrm{Fe}^{3+}$ in melt, we adopt a force constant of $351 \mathrm{~N} / \mathrm{m}$ (Fig. 5). The blue dashed curve shows the isotopic evolution of a residual melt assuming that in melts and minerals, the iron force constants are the same (i.e., $199 \mathrm{~N} / \mathrm{m}$ for $\mathrm{Fe}^{2+}$ and $255 \mathrm{~N} / \mathrm{m}$ for $\mathrm{Fe}^{3+}$ ). In this case, late crystallization of $\mathrm{Fe}^{3+}$-rich (isotopically heavy) magnetite drives the magma towards low $\delta^{56} \mathrm{Fe}$ values, which cannot explain the data. The red continuous curve shows the isotopic evolution of the residual magma taking into account the force constants measured here. This explains the data, indicating that fractional crystallization is probably responsible for the high $\delta^{56} \mathrm{Fe}$ values measured in natural granitoids and rhyolites.

duces well the trend in $\delta^{56} \mathrm{Fe}$ vs. $\mathrm{SiO}_{2}$ measured in silicic rocks (Fig. 9B), indicating that fractional crystallization is most likely responsible for the fractionated Fe isotopic compositions of silicarich granites and rhyolites. The Fe isotopic composition of some granitoids and pegmatites may have been affected by fluid exsolution but this process is better traced by using isotope variations of other base metals such as copper or zinc (Telus et al., 2012).

\section{Conclusion}

Chemical compositions have provided invaluable constraints on the petrogenetic processes that shaped terrestrial planets but there are many outstanding questions that call for the development of new proxies. Measurements of non-traditional stable isotopes in magmatic systems have revealed variations that have proven to be difficult to interpret due to lack of knowledge of equilibrium stable isotopic fractionation between phases at high temperature. In particular, measurements of granitoids and oceanic basalts have revealed significant stable isotope variations that cannot be ascribed unambiguously to a specific process. Iron is particularly interesting because its three oxidation states $\mathrm{Fe}^{0}, \mathrm{Fe}^{2+}$, and $\mathrm{Fe}^{3+}$ are partitioned differently between the core, mantle and crust, raising the possibility of tracing redox processes in Earth using Fe stable isotope variations. The synchrotron method of NRIXS allows one to directly measure the mean force constant of iron bonds, from which equilibrium isotope fractionation factors can be derived. We have synthesized olivine as well as glasses of basaltic, andesitic, dacitic and rhyolitic compositions under controlled oxygen fugacities.

The Fe force constant measured in these glasses by NRIXS increases linearly with $\mathrm{Fe}^{3+} / \mathrm{Fe}_{\text {tot }}$ ratio measured by conventional Mössbauer spectroscopy. Basalt, andesite, and dacite glasses define a single trend in force constant vs. $\mathrm{Fe}^{3+} / \mathrm{Fe}_{\text {tot }}$ ratio while rhyolite glasses defines a different trend. By extrapolating the force constants to $\mathrm{Fe}^{3+} / \mathrm{Fe}_{\text {tot }}=0$ and $\mathrm{Fe}^{3+} / \mathrm{Fe}_{\text {tot }}=1$, we estimate the following values for the force constants: $\mathrm{Fe}^{2+}$ in basalt-andesitedacite $=199 \pm 15 \mathrm{~N} / \mathrm{m} ; \mathrm{Fe}^{2+}$ in rhyolite $=240 \pm 13 \mathrm{~N} / \mathrm{m} ; \mathrm{Fe}^{3+}$ in basalt-andesite-dacite $=351 \pm 29 \mathrm{~N} / \mathrm{m} ; \mathrm{Fe}^{3+}$ in rhyolite $=$ $385 \pm 24 \mathrm{~N} / \mathrm{m}$. Olivine $(197 \pm 10 \mathrm{~N} / \mathrm{m})$ has a force constant that is similar to previously published NRIXS values for pyroxenes and is also similar to $\mathrm{Fe}^{2+}$ in basalt. The fact that $\mathrm{Fe}^{2+}$ in basalt has the same force constant as Fe in olivine and pyroxene is consistent with the absence of isotopic fractionation between HED (Vesta) and SNC (Mars) meteorites on the one hand, and chondrites on the other hand. However, it does not explain why angrites and terrestrial basalts have heavy $\mathrm{Fe}$ isotopic compositions relative to chondrites. The force constant results are used in a model of isotopic fractionation during partial melting. MORBs are fractionated by $+0.08 \%$ in $\delta^{56} \mathrm{Fe}$ relative to their source rocks (abyssal peridotites). The new force constant data can explain isotopic fractionation upon melting of $\sim+0.023 \%$, which is insufficient to explain MORB values. Further work is needed to evaluate the effects of temperature and pressure on iron force constant determinations.

The force constant of $\mathrm{Fe}^{2+}$ in rhyolite is higher than those of $\mathrm{Fe}^{2+}$ in basalt, andesite, and dacite, suggesting a structural change of $\mathrm{Fe}^{2+}$ in the most silicic magmas. To further investigate this question, we have acquired XANES spectra of the glasses investigated by NRIXS and Mössbauer spectroscopies. The centroid energy of the XANES spectrum increases with the $\mathrm{Fe}^{3+} / \mathrm{Fe}_{\text {tot }}$ ratio. Our results expand previous work that was confined to basalt and rhyolite to intermediate compositions andesite and dacite. The trends in centroid energy vs. $\mathrm{Fe}^{3+} / \mathrm{Fe}_{\text {tot }}$ are indistinguishable for basalt, andesite and dacite but rhyolite plots on a different trend. This confirms the view that $\mathrm{Fe}^{2+}$ in rhyolite is in a different coordination environment than in less silicic magmas. The new XANES calibration can be used to measure in situ Fe redox state in glasses of basaltic to rhyolitic compositions.

The new set of force constant estimates is used in a model of andesitic magma differentiation using the rhyolite-MELTS software. As the magma becomes more silicic, equilibrium fractionation between magma and crystallizing minerals increases, which explains why granitoids and rhyolites tend to have heavy Fe isotopic compositions. Previous studies had speculated that fluid exsolution or Soret effect could have been responsible for Fe isotopic fractionation in magmas. Our results show that magma differentiation is the main driver for Fe isotopic fractionation in silicic magmas, although fluid exsolution may still play a role in pegmatites but this is better traced using other fluid mobile elements such as $\mathrm{Li}, \mathrm{Zn}$, or $\mathrm{Cu}$.

Our results demonstrate for the first time that stable isotope variations of $\mathrm{Fe}$, and of possibly other heterovalent elements such 
as $\mathrm{Ti}, \mathrm{V} \mathrm{Eu}, \mathrm{Cr}$, Ce, or $\mathrm{U}$, record redox and structural changes in melts. Of these elements, Eu is especially promising because ${ }^{151} \mathrm{Eu}$ is a Mössbauer sensitive isotope and therefore, a similar NRIXS approach can be used.

\section{Acknowledgements}

N.D. thanks the NSF Petrology and Geochemistry (EAR1144429) and NASA Cosmochemistry (NNX12AH60G) programs for support. M.R. thanks the support of the French ANR program (2011JS56 004 01, FrIHIDDA). The EPMA facility in Lille is supported by the European Regional Development Fund (ERDF). Constructive criticisms by Elizabeth Cottrell, Sune Nielsen, an anonymous reviewer, and editor Bernard Marty helped improve the manuscript. Discussions with Andrew J. Campbell, Jennifer M. Jackson and Wenli Bi were greatly appreciated.

\section{Appendix A. Evaluation of uncertainties in NRIXS moments}

The NRIXS spectrum is measured with an energy step size of $\Delta$. The $l$ th central moment of $S$ is calculated as follows:

$R_{l}=\sum_{i}\left(E_{i}-E_{R}\right)^{l} S_{i} \Delta$,

where $E_{i}$ and $S_{i}$ are the energy and scattered signal in energy bin $i$. The scattering function is proportional, through a normalization factor $x$, to the number of counts in the measured spectrum, which has uncertainties given by Poisson statistics. The energies are determined by the motions of high-resolution monochromator crystals, which can introduce some energy scaling or offset errors. The scattered signal also has to be corrected for baseline counts, which we assume vary linearly with energy and are estimated by interpolating the measured baseline at the low and high tails of the acquisition window. To take into account these possible errors, we rewrite the previous equation as

$R_{l}=\sum_{i}\left(\gamma E_{i}+\varepsilon-E_{R}\right)^{l}\left(S_{i}-a E_{i}-b\right) \Delta$.

The uncertainties can be propagated by calculating the partial derivatives of $R_{l}$ relative to the parameters (some of these formulas had been derived by Hu et al., 2013):

$\partial R_{l} / \partial \gamma=\sum_{i} E_{i} l\left(\gamma E_{i}+\varepsilon-E_{R}\right)^{l-1}\left(S_{i}-a E_{i}-b\right) \Delta$.

Because $\gamma \simeq 1$ and $E_{i} \gg \varepsilon-E_{R}$ this equation can be approximated as (Eq. (73) of Hu et al., 2013),

$\partial R_{l} / \partial \gamma \simeq l R_{l}$.

$\partial R_{l} / \partial \varepsilon=\sum_{i} l\left(\gamma E_{i}+\varepsilon-E_{R}\right)^{l-1}\left(S_{i}-a E_{i}-b\right) \Delta$.

$\partial R_{l} / \partial \varepsilon=l R_{l-1}$

$\partial R_{l} / \partial b=-\sum_{i}\left(\gamma E_{i}+\varepsilon-E_{R}\right)^{l} \Delta$.

It is convenient to use here the integral notation,

$\partial R_{l} / \partial b=-\int_{E_{\min }}^{E_{\max }}\left(E-E_{R}\right)^{l} d E$.

We therefore have (Eq. (67) of Hu et al., 2013).

$\partial R_{l} / \partial b=-\frac{\left(E_{\max }-E_{R}\right)^{l+1}-\left(E_{\min }-E_{R}\right)^{l+1}}{l+1}$.

$\partial R_{l} / \partial a=-\sum_{i}\left(\gamma E_{i}+\varepsilon-E_{R}\right)^{l} E_{i} \Delta$.
Using the integral notation, we have,

$$
\begin{aligned}
\partial R_{l} / \partial a= & -\int_{E_{\min }}^{E_{\max }}\left(E-E_{R}\right)^{l} E d E . \\
\partial R_{l} / \partial a= & -\left(E_{\max }-E_{R}\right)^{l+1}\left(E_{\max }+l E_{\max }+E_{R}\right) \\
& \left.-\left(E_{\min }-E_{R}\right)^{l+1}\left(E_{\min }+l E_{\min }+E_{R}\right)\right] \\
& \times(l+1)(l+2)]^{-1} .
\end{aligned}
$$

This is well approximated by

$\partial R_{l} / \partial a \simeq-\frac{\left(E_{\max }-E_{R}\right)^{l+1} E_{\max }-\left(E_{\min }-E_{R}\right)^{l+1} E_{\min }}{l+2}$.

$\partial R_{l} / \partial S_{i}=\left(\gamma E_{i}+\varepsilon-E_{R}\right)^{l} \Delta$

$\sum_{i}\left(\partial R_{l} / \partial S_{i}\right)^{2} \sigma_{S i}^{2}=\sum_{i}\left(\gamma E_{i}+\varepsilon-E_{R}\right)^{2 l} \Delta^{2} \sigma_{S i}^{2}$.

Because $\sigma_{S i}^{2}=x S_{i}$ (Poisson statistics), we have (Eq. (67) of $\mathrm{Hu}$ et al., 2013),

$\sum_{i}\left(\partial R_{l} / \partial S_{i}\right)^{2} \sigma_{S i}^{2}=x \Delta R_{2 l}$

The overall uncertainty on $R_{l}$ is therefore,

$$
\begin{aligned}
\sigma_{R l}^{2}= & \left(l R_{l}\right)^{2} \sigma_{\gamma}^{2}+\left(l R_{l-1}\right)^{2} \sigma_{\varepsilon}^{2} \\
& +\left[\frac{\left(E_{\max }-E_{R}\right)^{l+1}-\left(E_{\min }-E_{R}\right)^{l+1}}{l+1}\right]^{2} \sigma_{b}^{2} \\
& +\left[\frac{\left(E_{\max }-E_{R}\right)^{l+1} E_{\max }-\left(E_{\min }-E_{R}\right)^{l+1} E_{\min }}{l+2}\right]^{2} \sigma_{a}^{2} \\
& +x \Delta R_{2 l} .
\end{aligned}
$$

\section{Appendix B. Supplementary material}

Supplementary material related to this article can be found online at http://dx.doi.org/10.1016/j.epsl.2014.04.033.

\section{References}

Alberto, H.V., Pinto da Cunha, J.L., Mysen, B.O., Gil, J.M., de Campos, N.A., 1996. Analysis of Mössbauer spectra of silicate glasses using a two-dimensional Gaussian distribution of hyperfine parameters. J. Non-Cryst. Solids 194, 48-57.

Beard, B.L., Johnson, C.M., 2007. Comment on "Iron isotope fractionation during planetary differentiation". Earth Planet. Sci. Lett. 256, 633-637.

Beard, B.L., Johnson, C.M., Skulan, J.L., Nealson, K.H., Cox, L., Sun, H., 2003. Application of Fe isotopes to tracing the geochemical and biological cycling of Fe. Chem. Geol. 195, 87-117.

Bezos, A., Humler, E., 2005. The $\mathrm{Fe}^{3+} / \mathrm{Fe}_{\text {tot }}$ ratios of MORB glasses and their implications for mantle melting. Geochim. Cosmochim. Acta 69, 711-725.

Bigeleisen, J., Goeppert-Mayer, M.G., 1947. Calculation of equilibrium constants for isotopic exchange reactions. J. Chem. Phys. 15, 261-267.

Brearly, M., 1990. Ferric iron in silicate melts in the system $\mathrm{Na}_{2} \mathrm{O}-\mathrm{Fe}_{2} \mathrm{O}_{3}-\mathrm{SiO}_{2}$ at high pressure. J. Geophys. Res. 95 (B10), 15703-15716.

Canil, D., O'Neill, H.St.C., Pearson, D.G., Rudnick, R.L., McDonough, W.F., Carswell, D.A., 1994. Ferric iron in peridotites and mantle oxidation states. Earth Planet. Sci. Lett. 123, 205-220.

Chumakov, A.I., Sturhahn, W., 1999. Experimental aspects of inelastic nuclear resonance scattering. Hyperfine Interact. 123-124, 781-808.

Clemens, J.D., Holloway, J.R., White, A.J.R., 1986. Origin of an A-type granite: experimental constraints. Am. Mineral. 71, 317-324.

Cottrell, E., Kelley, K.A., 2011. The oxidation state of Fe in MORB glasses and the oxygen fugacity of the upper mantle. Earth Planet. Sci. Lett. 305, 270-282.

Cottrell, E., Kelley, K.A., 2013. Redox heterogeneity in mid-ocean ridge basalts as a function of mantle source. Science 340, 1314-1317.

Cottrell, E., Kelley, K.A., Lanzirotti, A., Fischer, R.A., 2009. High-precision determination of iron oxidation state in silicate glasses using XANES. Chem. Geol. 268, 167-179. 
Craddock, P.R., Dauphas, N., 2011. Iron isotopic compositions of geological reference materials and chondrites. Geostand. Geoanal. Res. 35, 101-123.

Craddock, P.R., Warren, J.M., Dauphas, N., 2013. Abyssal peridotites reveal the nearchondritic Fe isotopic composition of the Earth. Earth Planet. Sci. Lett. 365, 63-76.

Dauphas, N., Rouxel, O., 2006. Mass spectrometry and natural variations of iron isotopes. Mass Spectrom. Rev. 25, 515-550. Mass Spectrom. Rev. 25 (2006) 831-832 (Erratum)

Dauphas, N., Craddock, P.R., Asimow, P.D., Bennett, V.C., Nutman, A.P., Ohnenstetter, D., 2009a. Iron isotopes may reveal the redox conditions of mantle melting from Archean to present. Earth Planet. Sci. Lett. 288, 255-267.

Dauphas, N., Pourmand, A., Teng, F.-Z., 2009b. Routine isotopic analysis of iron by HR-MC-ICPMS: how precise and how accurate? Chem. Geol. 267, 175-184.

Dauphas, N., Teng, F.-Z., Arndt, N.T., 2010. Magnesium and iron isotopes in $2.7 \mathrm{Ga}$ Alexo komatiites: mantle signatures, no evidence for Soret diffusion, and identification of diffusive transport in zoned olivine. Geochim. Cosmochim. Acta 74, 3274-3291.

Dauphas, N., Roskosz, M., Alp, E.E., Golden, D.C., Sio, C.K., Tissot, F.L.H., Hu, M.Y., Zhao, J., Gao, L., Morris, R.V., 2012. A general moment NRIXS approach to the determination of equilibrium $\mathrm{Fe}$ isotopic fractionation factors: application to goethite and jarosite. Geochim. Cosmochim. Acta 94, 254-275.

DePaolo, D.J., 2004. Calcium isotopic variations produced by biological, kinetic, radiogenic and nucleosynthetic processes. In: Rosso, Jodi (Ed.), Mineralogy and Geochemistry, vol. 55, pp. 255-288. Chapter in Reviews.

Fitoussi, C., Bourdon, B., Kleine, T., Oberli, F., Reynolds, R.C., 2009. Si isotope systematics of meteorites and terrestrial peridotites: implications for $\mathrm{Mg} / \mathrm{Si}$ fractionation in the solar nebula and for Si in Earth's core. Earth Planet. Sci. Lett. 287, 77-85.

Galoisy, L., Calas, G., Arrio, M.A., 2001. High-resolution XANES spectra of iron in minerals and glasses: structural information from the pre-edge region. Chem. Geol. 174, 307-319.

Georg, R.B., Halliday, A.N., Schauble, E.A., Reynolds, B.C., 2007. Silicon in the Earth's core. Nature 447, 1102-1106.

Giuli, G., Alonso-Mori, R., Rita Cicconi, M., Paris, E., Glatzel, P., Griet Eeckhout, S. Scaillet, B., 2012. Effect of alkalis on the Fe oxidation state and local environment in peralkaline rhyolitic glasses. Am. Mineral. 97, 468-475.

Grove, T.L., 1981. Use of FePt alloys to eliminate the Fe loss problem in 1 atmosphere gas mixing experiments: theoretical and practical considerations. Contrib. Mineral. Petrol. 78, 298-304.

Gualda, G.A.R., Ghiorso, M.S., Lemons, R.V., Carley, T.L., 2012. Rhyolite-MELTS: a modified calibration of MELTS optimized for silica-rich, fluid-bearing magmatic systems. J. Petrol. 53, 875-890.

Gudmundsson, G., Holloway, J.R., 1993. Activity-composition relationships in the system Fe-Pt at 1300 and $1400{ }^{\circ} \mathrm{C}$ and at 1 atm and 20 kbar. Am. Mineral. 78 , $178-186$

Handler, M.R., Baker, J.A., Schiller, M., Bennett, V.C., Yaxley, G.M., 2009. Magnesium stable isotope composition of Earth's upper mantle. Earth Planet. Sci. Lett. 282, 306-313.

Heimann, A., Beard, B.L., Johnson, C.M., 2008. The role of volatile exsolution and sub-solidus fluid/rock interactions in producing high ${ }^{56} \mathrm{Fe} /{ }^{54} \mathrm{Fe}$ ratios in siliceous igneous rocks. Geochim. Cosmochim. Acta 72, 4379-4396.

Herzfeld, K.F., Teller, E., 1938. The vapor pressure of isotopes. Phys. Rev. 54, 912-915.

Hibbert, K.E.J., Williams, H.M., Kerr, A.C., Puchtel, I.S., 2012. Iron isotopes in ancient and modern komatiites: evidence in support of an oxidized mantle from Archean to present. Earth Planet. Sci. Lett. 321-322, 198-207.

Hin, R.C., Schmidt, M.W., Bourdon, B., 2012. Experimental evidence for the absence of iron isotope fractionation between metal and silicate liquids at $1 \mathrm{GPa}$ and $1250-1300^{\circ} \mathrm{C}$ and its cosmochemical consequences. Geochim. Cosmochim. Acta 93, 164-181.

Hu, M.Y., Toellner, T.S., Dauphas, N., Alp, E.E., Zhao, J., 2013. Moments in nuclear resonant inelastic X-ray scattering and their applications. Phys. Rev. B 87064301.

Huang, S., Farkas, J., Jacobsen, S.B., 2011. Stable calcium isotopic compositions of Hawaiian shield lavas: evidence for recycling of ancient marine carbonates into the mantle. Geochim. Cosmochim. Acta 75, 4987-4997.

Humayun, M., Clayton, R.N., 1995. Precise determination of the isotopic composition of potassium: application to terrestrial rocks and lunar soils. Geochim. Cosmochim. Acta 59, 2115-2130.

Jackson, W.E., Farges, F., Yeager, M., Mabrouk, P.A., Rossano, S., Waychunas, G.A. Solomon, E.I., Brown, G.E., 2005. Multi-spectroscopic study of $\mathrm{Fe}(\mathrm{II})$ in silicate glasses: implications for the coordination environment of $\mathrm{Fe}(\mathrm{II})$ in silicate melts. Geochim. Cosmochim. Acta 69, 4315-4332.

Jackson, J.M., Hamecher, E.A., Sturhahn, W., 2009. Nuclear resonant X-ray spectroscopy of $(\mathrm{Mg}, \mathrm{Fe}) \mathrm{SiO}_{3}$ orthoenstatites. Eur. J. Mineral. 21, 551-560.

Jayasuriya, K.D., O’Neill, H.St.C., Berry, A.J., Campbell, S.J., 2004. A Mössbauer study of the oxidation state of Fe in silicate melts. Am. Mineral. 89, 1597-1609.

Jordan, M.K., Young, E.D., 2014. Equilibrium metal-silicate Fe isotope fractionation and the implications for differentiation in planetary interiors. Lunar Planet. Sci. Conf. Abstr. 45, \#2318.

Jurewicz, A.J.G., Mittlefehldt, D.W., Jones, J.H., 1991. Partial melting of the Allende (CV3) meteorite - implications for origins of basaltic meteorites. Science 252, 695-698.
Jurewicz, A.J.G., Mittlefehldt, D.W., Jones, J.H., 1993. Experimental partial melting of the Allende (CV) and Murchison (CM) chondrites and the origin of asteroidal basalts. Geochim. Cosmochim. Acta 57, 2123-2139.

Klein, E.M., Langmuir, C.H., 1987. Global correlations of ocean ridge basalt chemistry with axial depth and crustal thickness. J. Geophys. Res. 92, 8089-8115.

Krawczynski, M.J., Van Orman, J.A., Dauphas, N., Alp, E.E., Hu, M., 2014. Iron isotope fractionation between metal and troilite: a new cooling speedometer for iron meteorites. In: 45th Lunar and Planetary Sience Conference, \#2755.

Lagarec, K., Rancourt, D.G., 1997. Extended Voigt-based analytical lineshape method for determining $\mathrm{N}$-dimensional correlated hyperfine parameter distributions in Mössbauer spectroscopy. Nucl. Instrum. Methods Phys. Res., Sect. B, Beam Interact. Mater. Atoms 129, 266-280.

Lipkin, H.J., 1995. Mössbauer sum rules for use with synchrotron sources. Phys. Rev. B 52, 10073.

Lipkin, H.J., 1999. Mössbauer sum rules for use with synchrotron sources. Hyperfine Interact. 123-124, 349-366.

Liu, Y., Spicuzza, M.J., Craddock, P.R., Day, J.M.D., Valley, J.W., Dauphas, N., Taylor, L.A., 2010. Oxygen and iron isotope constraints on near-surface fractionation effects and the composition of lunar mare basalt source regions. Geochim. Cosmochim. Acta 74, 6249-6262.

Lundstrom, C., 2009. Hypothesis for the origin of convergent margin granitoids and Earth's continental crust by thermal migration zone refining. Geochim. Cosmochim. Acta 73, 5709-5729.

Magnien, V., Neuville, D.R., Cormier, L., Mysen, B.O., Richet, P., 2004. Kinetics of iron oxidation in silicate melts: a preliminary XANES study. Chem. Geol. 213, 253-263.

Magnien, V., Neuville, D.R., Cormier, L., Roux, J., Hazemann, J.-L., de Ligny, D., Pascarelli, S., Vickridge, I., Pinet, O., Richet, P., 2008. Kinetics and mechanisms of iron redox reactions in silicate melts: the effects of temperature and alkali cations. Geochim. Cosmochim. Acta 72, 2157-2168.

Mallmann, G., O'Neill, H.S.C., 2009. The crystal/melt partitioning of V during mantle melting as a function of oxygen fugacity compared with some other elements (Al, P, Ca, Sc, Ti, Cr, Fe, Ga, Y, Zr and Nb). J. Petrol. 50, 1765-1794.

Mallmann, G. O'Neill, H.S.C., 2013. Calibration of an empirical thermometer and oxybarometer based on the partitioning of Sc, Y and V between olivine and silicate melt. J. Petrol. 54, 933-949.

McKay, G., Le, L., Wagstaff, J., Crozaz, G., 1994. Experimental partitioning of rareearth elements and strontium - constraints on petrogenesis and redox conditions during crystallization of antarctic angrite Lewis Cliff-86010. Geochim. Cosmochim. Acta 58, 2911-2919.

McKenzie, D., Bickle, M.J., 1988. The volume and composition of melt generated by extension of the lithosphere. J. Petrol. 29, 625-679.

Médard, E., Schmidt, M.W., Schiano, P., Ottolini, L., 2006. Melting of amphibolebearing wehrlites: an experimental study on the origin of ultra-calcic nephelinenormative melts. J. Petrol. 47, 481-504.

Métrich, N., Susini, J., Foy, E., Farges, F., Massare, D., Sylla, L., Lequien, S., BonninMosbah, M., 2006. Redox state of iron in peralkalin rhyolitic glass/melt: Xray absorption micro-spectroscopy experiments at high temperature. Chem. Geol. 231, 350-363.

Millet, M.-A., Baker, J.A., Payne, C.E., 2012. Ultra-precise stable Fe isotope measurements by high resolution multiple-collector inductively coupled plasma mass spectrometry with a ${ }^{57} \mathrm{Fe}-{ }^{58} \mathrm{Fe}$ double spike. Chem. Geol. 304-305, 18-25.

Mysen, B.O., Virgo, D., 1985. Iron-bearing silicate melts: relations between pressure and redox equilibria. Phys. Chem. Miner. 12, 191-200.

Poitrasson, F., Freydier, R., 2005. Heavy iron isotope composition of granites determined by high resolution MC-ICP-MS. Chem. Geol. 222, 132-147.

Poitrasson, F., Halliday, A.N., Lee, D.C., Levasseur, S., Teutsch, N., 2004. Iron isotope differences between Earth, Moon, Mars and Vesta as possible records of contrasted accretion mechanisms. Earth Planet. Sci. Lett. 223, 253-266.

Poitrasson, F., Levasseur, S., Teutsch, N., 2005. Significance of iron isotope mineral fractionation in pallasites and iron meteorites for the core-mantle differentiation of terrestrial planets. Earth Planet. Sci. Lett. 234, 151-164.

Poitrasson, F., Roskosz, M., Corgne, A., 2009. No iron isotope fractionation between molten alloys and silicate melt to $2000^{\circ} \mathrm{C}$ and $7.7 \mathrm{GPa}$ : experimental evidence and implications for planetary differentiation and accretion. Earth Planet. Sci. Lett. 278, 376-385.

Poitrasson, F., Delpech, G., Gregoire, M., 2013. On the iron isotope heterogeneity of lithospheric mantle xenoliths: implications for mantle metasomatism, the origin of basalts and the iron isotope composition of the Earth. Contrib. Mineral. Petrol. 165, 1243-1258.

Polyakov, V.B., 2009. Equilibrium iron isotope fractionation at core-mantle boundary conditions. Science 323, 912-914.

Polyakov, V.B., Mineev, S.D., 2000. The use of Mössbauer spectroscopy in stable isotope geochemistry. Geochim. Cosmochim. Acta 64, 849-865.

Polyakov, V.B., Mineev, S.D., Clayton, R.N., Hu, G., Mineev, K.S., 2005. Determination of tin equilibrium isotope fractionation factors from synchrotron radiation experiments. Geochim. Cosmochim. Acta 69, 5531-5536.

Polyakov, V.B., Clayton, R.N., Horita, J., Mineev, S.D., 2007. Equilibrium iron isotope fractionation factors of minerals: reevaluation from the data of nuclear inelastic resonant X-ray scattering and Mössbauer spectroscopy. Geochim. Cosmochim. Acta 71, 3833-3846. 
Roskosz, M., Luais, B., Watson, H.C., Toplis, M.J., Alexander, C.M.O’D., Mysen, B., 2006. Experimental quantification of the fractionation of Fe isotopes during metal segregation from a silicate melt. Earth Planet. Sci. Lett. 248, 851-867.

Roskosz, M., Toplis, M.J., Neuville, D.R., Mysen, B.O., 2008. Quantification of the kinetics of iron oxidation in silicate melts using Raman spectroscopy: what role of oxygen diffusion? Am. Mineral. 93, 1749-1759.

Rossano, S., Balan, B., Morin, G., Bauer, J.-P., Calas, G., Brouder, C., 1999. ${ }^{57}$ Fe Mössbauer spectroscopy of tektites. Phys. Chem. Miner. 26, 530-538.

Ruffoni, M.P., Pettifer, R.F., 2006. Calibration of XANES spectra from dispersive XAS beamline. J. Synchrotron Radiat. 13, 489-493.

Savage, P.S., Georg, R.B., Armytage, R.M.G., Williams, H.M., Halliday, A.N., 2010. Silicon isotope homogeneity in the mantle. Earth Planet. Sci. Lett. 295, 139-146.

Schoenberg, R., von Blanckenburg, F., 2006. Modes of planetary-scale Fe isotope fractionation. Earth Planet. Sci. Lett. 252, 342-359.

Schuessler, J.A., Schoenberg, R., Behrens, H., Von Blanckenburg, F., 2007. The experimental calibration of the iron isotope fractionation factor between pyrrhotite and peralkaline rhyolitic melt. Geochim. Cosmochim. Acta 71, 417-433.

Schuessler, J., Schoenberg, R., Sigmarsson, O., 2009. Iron and lithium isotope systematics of the Hekla volcano, Iceland-evidence for Fe isotope fractionation during magma differentiation. Chem. Geol. 258, 78-91.

Seto, M., Yoda, Y., Kikuta, S., Zhang, X.W., Ando, M., 1995. Observation of nuclear resonant scattering accompanied by phonon excitation using synchrotron radiation. Phys. Rev. Lett. 74, 3828-3831.

Seto, M., Kitao, S., Kobayashi, Y., Haruki, R., Yoda, Y., Mitsui, T., Ishikawa, T., 2003. Site-specific phonon density of states discerned using electronic states. Phys. Rev. Lett. 91 185505-1-185505-4.

Shahar, A., Young, E.D., Manning, C.E., 2008. Equilibrium high-temperature Fe isotope fractionation between fayalite and magnetite: an experimental calibration. Earth Planet. Sci. Lett. 268, 330-338.

Shahar, A., Hillgren, V.J., Mesa-Garcia, J., Horan, M.F., Mock, T.D., Deng, L., 2013. Iron isotope fractionation in an Fe-S alloy: implications for core formation. Lunar Planet. Sci. Conf. Abstr. 44, \#2351.

Simon, J.I., DePaolo, D.J., 2010. Stable calcium isotopic composition of meteorites and rocky planets. Earth Planet. Sci. Lett. 289, 457-466.

Sossi, P.A., Foden, J.D., Halverson, G.P., 2012. Redox-controlled iron isotope fractionation during magmatic differentiation: an example from the Red Hill intrusion, S. Tasmania. Contrib. Mineral. Petrol. 164, 757-772.

Sturhahn, W., 2000. CONUSS and PHOENIX: evaluation of nuclear resonant scattering data. Hyperfine Interact. 125, 149-172.

Sturhahn, W., Toellner, T.S., Alp, E.E., Zhang, X., Ando, M., Yoda, Y., Kikuta, S., Seto, M., Kimball, C.W., Dabrowski, B., 1995. Phonon density of states measured by inelastic nuclear resonant scattering. Phys. Rev. Lett. 74, 3832-3835.

Telus, M., Dauphas, N., Moynier, F., Tissot, F.L.H., Teng, F.-Z., Nabelek, P.I., Craddock, P.R., Groat, L.A., 2012. Iron, zinc, magnesium and uranium isotopic fractionation during continental crust differentiation: the tale from migmatites, granitoids, and pegmatites. Geochim. Cosmochim. Acta 97, 247-265.

Teng, F.-Z., Li, W.-Y., Ke, S., Marty, B., Dauphas, N., Huang, S., Wu, F.-Y., Pourmand, A. 2010. Magnesium isotopic composition of the Earth and chondrites. Geochim. Cosmochim. Acta 74, 4150-4166.

Teng, F.-Z., Dauphas, N., Huang, S., Marty, B., 2013. Iron isotopic systematics of oceanic basalts. Geochim. Cosmochim. Acta 107, 12-26.

Wang, K., Moynier, F., Dauphas, N., Barrat, J.-L., Craddock, P., Sio, C.K., 2012. Iron isotope fractionation in planetary crusts. Geochim. Cosmochim. Acta 89, 31-45.

Waychunas, G.A., Brown, G.E., Ponader, C.W., Jackson, W.E., 1988. Evidence from Xray absorption for network-forming $\mathrm{Fe}^{2+}$ in molten alkali silicates. Nature 3332, 251-253.

Weyer, S., Ionov, D.A., 2007. Partial melting and melt percolation in the mantle: the message from Fe isotopes. Earth Planet. Sci. Lett. 259, 119-133.

Weyer, S., Anbar, A.D., Brey, G.P., Munker, C., Mezger, K., Woodland, A.B., 2005. Iron isotope fractionation during planetary differentiation. Earth Planet. Sci. Lett. 240, 251-264.

Weyer, S., Anbar, A.D., Brey, G.P., Munker, C., Mezger, K., Woodland, A.B., 2007. Feisotope fractionation during partial melting on Earth and the current view on the Fe-isotope budgets of the planets (reply to the comment of F. Poitrasson and to the comment of B.L. Beard and C.M. Johnson). Earth Planet. Sci. Lett. 256, 638-646.

Wilke, M., Farges, F., Petit, P.-E., Brown Jr., G.E., Martin, F., 2001. Oxidation state and coordination of $\mathrm{Fe}$ in minerals: an Fe K-XANES spectroscopic study. Am. Mineral. 86, 714-730.

Wilke, M., Behrens, H., Burkhard, D.J.M., Rossano, S., 2002. The oxidation state of iron in silicic melt at $500 \mathrm{MPa}$ water pressure. Chem. Geol. 189, 55-67.

Wilke, M., Partzsch, G.M., Bernhardt, R., Lattard, D., 2005. Determination of the iron oxidation state in basaltic glasses using XANES at the K-edge. Chem. Geol. 220, 143-161.

Williams, H.M., McCammon, C.A., Peslier, A.H., Halliday, A.N., Teutsch, N., Levasseur, S., Burg, J.-P., 2004. Iron isotope fractionation and the oxygen fugacity of the mantle. Science 304, 1656-1659.

Williams, H.M., Wood, B.J., Wade, J., Frost, D.J. Tuff, J. 2012. Isotopic evidence for internal oxidation of the Earth's mantle during accretion. Earth Planet. Sci. Lett. 321-322, 54.

Winterer, M., 1997. A data analysis program for materials science. J. Phys. IV (C2), $243-244$.

Wolf, G.H., McMillan, P.F., 1995. Pressure effects on silicate melt structure and properties. Rev. Mineral. 32, 505-561.

Zambardi, T., Poitrasson, F., Corgne, A., Meheut, M., Quitte, G., Anand, M., 2013. Silicon isotope variations in the inner solar system: Implications for planetary formation, differentiation and composition. Geochim. Cosmochim. Acta 121, 67-83. 